Article

\title{
Evaluation and Mathematical Analysis of a Four-Dimensional Lotka-Volterra-like Equation Designed to Describe the Batch Nisin Production System
}

\author{
Fernando Giménez-Palomares ${ }^{1}$, Pedro Fernández de Córdoba ${ }^{1} \mathbb{D}$, Juan C. Mejuto ${ }^{2, *(\mathbb{D})}$, \\ Ricardo J. Bendaña-Jácome ${ }^{3}$ and Nelson Pérez-Guerra ${ }^{4, *}$
}

check for updates

Citation: Giménez-Palomares, F.; Fernández de Córdoba, P.; Mejuto, J.C.; Bendaña-Jácome, R.J.; Pérez-Guerra, N. Evaluation and Mathematical Analysis of a Four-Dimensional Lotka-Volterra-like Equation Designed to Describe the Batch Nisin Production System. Mathematics 2022, 10, 677. https://doi.org/10.3390/ math10050677

Academic Editors: Theodore E. Simos, Charampos Tsitouras and Christopher Goodrich

Received: 30 December 2021 Accepted: 16 February 2022 Published: 22 February 2022

Publisher's Note: MDPI stays neutral with regard to jurisdictional claims in published maps and institutional affiliations.

Copyright: (c) 2022 by the authors. Licensee MDPI, Basel, Switzerland. This article is an open access article distributed under the terms and conditions of the Creative Commons Attribution (CC BY) license (https:// creativecommons.org/licenses/by/ $4.0 /)$.
1 Instituto Universitario de Matemática Pura y Aplicada, Universitat Politècnica de València, Camino de Vera, s/n, 46022 Valencia, Spain; fgimenez@mat.upv.es (F.G.-P.); pfernandez@mat.upv.es (P.F.d.C.)

2 Department of Physical Chemistry, Faculty of Science, University of Vigo, 32004 Ourense, Spain

3 Department of Engineering, Materials, Structural Mechanics and Construction, Faculty of Sciences, University of Vigo, Ourense Campus, As Lagoas, s/n, 32004 Ourense, Spain; ricardojbj@uvigo.es

4 Department of Analytical and Food Chemistry, Faculty of Sciences, University of Vigo, Ourense Campus, As Lagoas, s/n, 32004 Ourense, Spain

* Correspondence: xmejuto@uvigo.es (J.C.M.); nelsonpg@uvigo.es (N.P.-G.); Tel.: +34-88-387-031 (J.C.M.); +34-88-387-053 (N.P.-G.)

\begin{abstract}
Nisin, an antibacterial compound produced by Lactococcus lactis strains, has been approved by the US Food and Drug Administration to be used as a safe food additive to control the growth of undesirable pathogenic bacteria. Nisin is commonly described as a $\mathrm{pH}$-dependent primary metabolite since its production depends on growth and culture $\mathrm{pH}$ evolution. However, the relationships between bacteriocin synthesis (BT), biomass production $(\mathrm{X})$, culture $\mathrm{pH}$, and the consumption of the limiting nutrient (total nitrogen: TN) have not been described until now. Therefore, this study aims to develop a competitive four-dimensional Lotka-Volterra-like Equation (predator-prey system) to describe these complex relationships in three series of batch fermentations with L. lactis CECT 539 in diluted whey (DW)-based media. The developed four-dimensional predator-prey system accurately described each individual culture, providing a good description of the relationships between $\mathrm{pH}, \mathrm{TN}, \mathrm{X}$, and BT, higher values for $R^{2}$ and $F$-ratios, lower values $(<10 \%)$ for the mean relative percentage deviation modulus, with bias and accuracy factor values approximately equal to one. The mathematical analysis of the developed equation showed the existence of one asymptotically stable equilibrium point, and the phase's diagram obtained did not show the closed elliptic trajectories observed in biological predator-prey systems.
\end{abstract}

Keywords: nisin; asymptotically stable equilibrium point; batch fermentation; four-dimensional predator-prey system; mathematical analysis

\section{Introduction}

Nisin, a bacteriocin produced by Lactococcus lactis strains, has a wide antibacterial activity against food spoilage and pathogenic bacteria. For this reason, this biomolecule has been recognized by the US Food and Drug Administration as a natural and safe biopreservative in food products, being allowed in the USA and several European Union countries. The advantages of using nisin in foods include the reduction in both the thermal treatment and addition of chemicals to food products and an increase in their shelf life [1].

For high nisin production at low cost, it is necessary to know the relationship between the main culture variables, which could be elucidated with the use of appropriate mathematical models. This could also allow proper monitoring and control of these bioprocesses [2].

Different mathematical models have been commonly used to describe the kinetics of growth (e.g., Verhulst, Gompertz, Richards, Bertalanffy, Weibull, and Monod) and 
bacteriocin synthesis (e.g., unmodified and modified forms of the Luedeking-Piret model) by lactic acid bacteria (LAB) in batch fermentations [2-8]. However, these models do not always provide an accurate or reasonable description of the bacteriocin production system.

An appropriate model for biomass production should consider the main factors affecting growth, including the effect of the time-dependent dynamics of other culture variables (culture $\mathrm{pH}$ and the concentrations of nutrients and products) $[2,3,5,9,10]$. In addition, a model describing nisin synthesis should relate the kinetics of product formation rate to the growth rate and biomass concentration [11], but if another factor (e.g., $\mathrm{pH}$ or an essential nutrient) produces a specific effect on product synthesis, a term for explaining such an effect should be included in the model $[5,9,12]$. To the best of our knowledge, there are no models describing the complex relationships between the dynamics of culture $\mathrm{pH}$ $(p H(t))$, the limiting nutrient consumption and production of biomass $(X(t))$, and bacteriocin $(B T(t))[5,9,11,12]$.

The three-dimensional Lotka-Volterra (LV) equations were designed for appropriately describing the interactions between three species (two preys-one predator or one prey-two predators) in biological systems [13]. Based on this fact, this three-dimensional LV-like equation was modified to explain, for the first time and in the simplest way, the relationships between the variables $p H(t), X(t)$, and $B T(t)$ in batch cultures of different LAB in various culture media [8]. Nevertheless, the modified three-dimensional equation neither accounts for the effect of total nitrogen $(T N(t))$ consumption (the growth limiting nutrient in these fermentations $[5,8]$ ) on the growth and nisin production, nor includes an equation to describe the dynamics of total nitrogen consumption for biomass and nisin synthesis. This was mainly due to some researchers not quantifying the evolution of $T N(t)$ in the cultures [14].

For this reason, in this study, a four-dimensional equation based on competitive predator-prey system assumptions [15] was developed for the first time, considering the interactions between the main culture variables $(p H(t), T N(t), X(t)$, and $B T(t))$ implicated in nisin production. Then, we investigated the effectiveness of the designed model for describing the microbiological bacteriocin production system of L. lactis CECT 539 in different batch fermentations in diluted whey (DW) media containing different initial nutrient compositions [16-18]. With this approach, an improved description of the complex relationships between the four variables was given.

The values of the biokinetic parameters for each equation were determined by the numerical integration of the four differential equations of the developed model, and their statistical significance was corroborated by using an appropriate statistical analysis. The adequacy and utility of the designed four-dimensional equation were discussed by taking into account the statistical significance of the model parameters, the trends observed in the experimental data, and the different culture media used. Furthermore, the mathematical analysis of the four-dimensional Lotka-Volterra-like equation was also performed by studying its approximated solutions, trajectories, and steady states.

\section{Results and Discussion}

\subsection{Design of the Four-Dimensional Equation}

The microbiological four-dimensional Equation (Equations (1)-(4)) was developed considering the following assumptions:

(i) The culture $\mathrm{pH}(p H(t))$ decline could be described as the difference between the buffer capacity of the medium [19] and the decrease in $\mathrm{pH}$ due to lactic acid production by the biomass as follows:

$$
\frac{d p H(t)}{d t}=-p H(t) \cdot(a-b \cdot p H(t)-c \cdot X(t))
$$

(ii) The total nitrogen $(T N(t))$, the limiting nutrient in these cultures [5], which is channeled into the cells and nisin molecules, could be considered as a prey that is consumed 
for both biomass and nisin production, and its consumption depends on the culture $\mathrm{pH}[5,20]$, as follows:

$$
\frac{d T N(t)}{d t}=-T N(t) \cdot(d-e \cdot T N(t)-f \cdot X(t)-g \cdot B T(t)-h \cdot p H(t))
$$

(iii) Biomass $(X(t))$ could be considered as one predator that grows logistically competing with nisin for the nitrogen source and depending on the culture $\mathrm{pH}$ and the TN source concentration [5], as follows:

$$
\frac{d X(t)}{d t}=X(t) \cdot(i-j \cdot X(t)-k \cdot B T(t)-l \cdot p H(t)-m \cdot T N(t))
$$

(iv) Nisin $(B T(t))$ could be considered as the second predator that is produced by the biomass but competes with it for the nitrogen source and depends on the culture $\mathrm{pH}$ and the TN source concentration [5], as follows:

$$
\frac{d B T(t)}{d t}=B T(t) \cdot(n-o \cdot B T(t)-p \cdot X(t)-q \cdot p H(t)-r \cdot T N(t))
$$

2.2. Modeling the Batch Nisin Production System in Different Series of Fermentations in DW Media Using a Global Set of Model Parameters

The capability of the four-dimensional predator-prey system (1)-(4) to describe the batch nisin production system was first assessed by adjusting a unique global set of equation parameters (general equation) to the entire set of experimental data in different series of batch cultures. The fermentations were performed in culture media (Tables 1 and 2) prepared with diluted whey (DW) containing the following different initials: (i) concentrations of glucose (DW-G series) [16], (ii) concentrations of total sugars and phosphorous (DW-TS-TP series) [17], or (iii) concentrations of MRS broth nutrients (DW-MRS series) [18].

Table 1. Initial concentrations (mean \pm standard deviations) of total sugars (TS), nitrogen (TN), phosphorous (TP), and proteins (Pr) in culture media prepared with deproteinized diluted whey (DW) and concentrated mussel-processing wastes (CMPW).

\begin{tabular}{ccccc}
\hline Medium & TS $(\mathrm{g} / \mathrm{L})$ & TN $(\mathrm{g} / \mathrm{L})$ & TP $(\mathrm{g} / \mathrm{L})$ & Pr $(\mathrm{g} / \mathrm{L})$ \\
\hline DW & $20.54 \pm 0.514$ & $0.45 \pm 0.014$ & $0.25 \pm 0.021$ & $2.04 \pm 0.083$ \\
DW25 & $20.96 \pm 0.021$ & $1.20 \pm 0.006$ & $0.30 \pm 0.001$ & $5.39 \pm 0.025$ \\
DW50 & $21.93 \pm 0.014$ & $1.96 \pm 0.013$ & $0.36 \pm 0.05$ & $8.72 \pm 0.034$ \\
DW75 & $22.89 \pm 0.016$ & $2.72 \pm 0.002$ & $0.43 \pm 0.07$ & $12.05 \pm 0.019$ \\
DW100 & $23.85 \pm 0.010$ & $3.49 \pm 0.016$ & $0.50 \pm 0.017$ & $15.38 \pm 0.031$ \\
DW125 & $24.81 \pm 0.023$ & $4.25 \pm 0.004$ & $0.57 \pm 0.013$ & $18.71 \pm 0.026$ \\
CMPW & $101.33 \pm 1.314$ & $0.54 \pm 0.024$ & $0.06 \pm 0.009$ & $3.47 \pm 0.046$ \\
\hline
\end{tabular}


Table 2. Initial concentrations (mean \pm standard deviations) of TS, TN, TP, and Pr in culture media prepared with DW medium mixed with different volumes of CMPW medium and supplemented with $\mathrm{KH}_{2} \mathrm{PO}_{4}$ to give different initial TS and TP concentrations (DW-TS-TP cultures).

\begin{tabular}{cccccc}
\hline Points & Experiment & TS $(\mathrm{g} / \mathrm{L})$ & TP $(\mathrm{g} / \mathrm{L})$ & TN $(\mathrm{g} / \mathrm{L})$ & $\operatorname{Pr}(\mathrm{g} / \mathrm{L})$ \\
\hline & 1 & $48.321 \pm 0.001$ & $0.589 \pm 0.001$ & $0.479 \pm 0.002$ & $2.531 \pm 0.018$ \\
& 2 & $48.321 \pm 0.001$ & $0.281 \pm 0.001$ & $0.479 \pm 0.002$ & $2.531 \pm 0.018$ \\
Factorial & 3 & $25.639 \pm 0.001$ & $0.589 \pm 0.001$ & $0.453 \pm 0.003$ & $2.122 \pm 0.028$ \\
& 4 & $25.639 \pm 0.001$ & $0.281 \pm 0.001$ & $0.453 \pm 0.003$ & $2.122 \pm 0.028$ \\
\hline & 5 & $51.352 \pm 0.003$ & $0.435 \pm 0.002$ & $0.483 \pm 0.001$ & $2.583 \pm 0.047$ \\
Axial & 6 & $22.611 \pm 0.001$ & $0.435 \pm 0.002$ & $0.450 \pm 0.001$ & $2.068 \pm 0.012$ \\
& 7 & $36.984 \pm 0.002$ & $0.631 \pm 0.003$ & $0.466 \pm 0.002$ & $2.318 \pm 0.026$ \\
Center (five & 8 & $36.984 \pm 0.002$ & $0.240 \pm 0.001$ & $0.466 \pm 0.002$ & $2.318 \pm 0.026$ \\
replicates) & $9-13$ & $36.984 \pm 0.002$ & $0.435 \pm 0.001$ & $0.466 \pm 0.002$ & $2.318 \pm 0.026$ \\
\hline
\end{tabular}

The data (symbols) corresponding to the four series of batch cultures [16-18] and the corresponding predictions (dashed lines) of the developed four-dimensional predator-prey system (1)-(4) are shown in Figures 1-4. The values for the constants and the statistical analysis of each equation in each series of cultures are shown in Table 3.

Table 3. Parameter values (as estimates \pm confidence intervals) calculated with the global set of model parameters of the four-dimensional predator-prey system (1)-(4) to describe the batch nisin production system in the different series of fermentations.

\begin{tabular}{cccc}
\hline Parameter & DW-G Series & DW-TS-TP Series & DW-MRS Series \\
\hline$a$ & $-0.155 \pm 0.039$ & $-0.083 \pm 0.022$ & $-0.105 \pm 0.022$ \\
& $(p=0.0001)$ & $(p=0.0003)$ & $(p<0.0001)$ \\
$b$ & $-0.036 \pm 0.007$ & $-0.019 \pm 0.003$ & $-0.0229 \pm 0.003$ \\
& $(p<0.0001)$ & $(p<0.0001)$ & $(p=0.0001)$ \\
$c$ & $0.040 \pm 0.018$ & $0.006 \pm 0.009$ & $-0.018 \pm 0.010$ \\
$R_{p H}{ }^{2}$ & $(p=0.0254)$ & $(p=0.5015)$ & $(p=0.0023)$ \\
$R P D M$ & 0.5382 & 0.8603 & 0.6108 \\
$B_{f}$ & 10.9930 & 10.1454 & 13.8907 \\
$A_{f}$ & 0.8972 & 0.9516 & 0.9999 \\
$F$-ratio & 1.1285 & 1.1001 & 1.1483 \\
$p$-value & 21.41 & 414.42 & 41.94 \\
& $<0.0001$ & $<0.0001$ & $<0.0001$ \\
\hline
\end{tabular}


Table 3. Cont.

\begin{tabular}{|c|c|c|c|}
\hline Parameter & DW-G Series & DW-TS-TP Series & DW-MRS Series \\
\hline$d$ & $\begin{array}{c}-0.087 \pm 0.022 \\
(p=0.0002)\end{array}$ & $\begin{array}{c}-0.034 \pm 0.029 \\
(p=0.2427)\end{array}$ & $\begin{array}{c}-0.163 \pm 0.060 \\
(p=0.0079)\end{array}$ \\
\hline$e$ & $\begin{array}{c}-0.636 \pm 0.055 \\
(p<0.0001)\end{array}$ & $\begin{array}{c}-0.512 \pm 0.056 \\
(p<0.0001)\end{array}$ & $\begin{array}{c}-0.012 \pm 0.002 \\
(p<0.0001)\end{array}$ \\
\hline$f$ & $\begin{array}{c}-0.081 \pm 0.010 \\
(p<0.0001)\end{array}$ & $\begin{array}{c}-0.123 \pm 0.014 \\
(p<0.0001)\end{array}$ & $\begin{array}{c}-0.346 \pm 0.052 \\
(p<0.0001)\end{array}$ \\
\hline$g$ & $\begin{array}{c}-0.0001 \pm 0.000 \\
\quad(p=0.4338)\end{array}$ & $\begin{array}{c}0.002 \pm 0.000 \\
(p<0.0001)\end{array}$ & $\begin{array}{l}0.004 \pm 0.0005 \\
(p<0.0001)\end{array}$ \\
\hline$h$ & $\begin{array}{c}0.032 \pm 0.001 \\
(p<0.0001)\end{array}$ & $\begin{array}{c}0.029 \pm 0.006 \\
(p<0.0001)\end{array}$ & $\begin{array}{c}-0.018 \pm 0.010 \\
(p=0.0602)\end{array}$ \\
\hline$R_{T N}^{2}$ & 0.9650 & 0.6909 & 0.2184 \\
\hline$R P D M$ & 1.4121 & 12.4855 & 20.6241 \\
\hline$B_{f}$ & 0.9745 & 1.0389 & 1.1310 \\
\hline$A_{f}$ & 1.0143 & 1.1077 & 1.1957 \\
\hline$F$-ratio & 349.16 & 66.00 & 22.58 \\
\hline$p$-value & $<0.0001$ & $<0.0001$ & 1.0000 \\
\hline$i$ & $\begin{array}{c}1.800 \pm 0.327 \\
(p<0.0001)\end{array}$ & $\begin{array}{c}2.381 \pm 0.150 \\
(p<0.0001)\end{array}$ & $\begin{array}{c}1.415 \pm 0.221 \\
(p<0.0001)\end{array}$ \\
\hline$j$ & $\begin{array}{c}1.376 \pm 0.098 \\
(p<0.0001)\end{array}$ & $\begin{array}{c}0.736 \pm 0.067 \\
(p<0.0001)\end{array}$ & $\begin{array}{c}0.366 \pm 0.078 \\
(p=0.0001)\end{array}$ \\
\hline$k$ & $\begin{array}{c}-0.007 \pm 0.001 \\
(p=0.0016)\end{array}$ & $\begin{array}{c}0.021 \pm 0.001 \\
(p<0.0001)\end{array}$ & $\begin{array}{c}0.006 \pm 0.002 \\
(p=0.0023)\end{array}$ \\
\hline$l$ & $\begin{array}{c}0.404 \pm 0.035 \\
(p=0.0016)\end{array}$ & $\begin{array}{l}0.262 \pm 0.0290 \\
(p<0.0001)\end{array}$ & $\begin{array}{c}0.227 \pm 0.040 \\
(p<0.0001)\end{array}$ \\
\hline$m$ & $\begin{array}{c}-1.880 \pm 0.432 \\
(p<0.0001)\end{array}$ & $\begin{array}{c}0.636 \pm 0.166 \\
(p=0.0002)\end{array}$ & $\begin{array}{c}-0.104 \pm 0.013 \\
(p<0.0001)\end{array}$ \\
\hline$R_{X}^{2}$ & 0.9669 & 0.8686 & 0.5670 \\
\hline$R P D M$ & 13.3796 & 25.9596 & 29.5432 \\
\hline$B_{f}$ & 0.9079 & 0.7488 & 0.8132 \\
\hline$A_{f}$ & 1.1626 & 1.4377 & 1.3899 \\
\hline$F$-ratio & 369.40 & 222.04 & 16.46 \\
\hline$p$-value & $<0.0001$ & $<0.0001$ & $<0.0001$ \\
\hline$n$ & $\begin{array}{c}3.730 \pm 0.335 \\
(p<0.0001)\end{array}$ & $\begin{array}{c}1.406 \pm 0.170 \\
(p<0.0001)\end{array}$ & $\begin{array}{c}0.232 \pm 0.141 \\
(p=0.0998)\end{array}$ \\
\hline$o$ & $\begin{array}{c}2.058 \times 10^{-5} \pm 0.004 \\
(p=0.9955)\end{array}$ & $\begin{array}{c}0.051 \pm 0.001 \\
(p<0.0001)\end{array}$ & $\begin{array}{c}0.002 \pm 0.001 \\
(p=0.0089)\end{array}$ \\
\hline$p$ & $\begin{array}{c}1.788 \pm 0.114 \\
(p<0.0001)\end{array}$ & $\begin{array}{c}-1.148 \pm 0.073 \\
(p<0.0001)\end{array}$ & $\begin{array}{c}0.136 \pm 74.506 \\
(p=0.0020)\end{array}$ \\
\hline$q$ & $\begin{array}{c}0.532 \pm 0.041 \\
(p<0.0001)\end{array}$ & $\begin{array}{c}0.260 \pm 0.030 \\
(p<0.0001)\end{array}$ & $\begin{array}{c}0.008 \pm 0.025 \\
(p=0.7806)\end{array}$ \\
\hline$r$ & $\begin{array}{c}0.984 \pm 1.295 \\
(p=0.4489)\end{array}$ & $\begin{array}{c}-0.723 \pm 0.140 \\
(p<0.0001)\end{array}$ & $\begin{array}{c}-0.051 \pm 0.008 \\
(p<0.0001)\end{array}$ \\
\hline$R_{B T^{2}}$ & 0.9001 & 0.9208 & 0.8890 \\
\hline$R P D M$ & 18.6672 & 34.7477 & 32.1298 \\
\hline$B_{f}$ & 0.8735 & 0.6200 & 0.7513 \\
\hline$A_{f}$ & 1.2311 & 1.9114 & 1.4540 \\
\hline$F$-ratio & 109.89 & 402.53 & 130.96 \\
\hline$p$-value & $<0.0001$ & $<0.0001$ & $<0.0001$ \\
\hline
\end{tabular}

The parameter value is considered statistically significant if its corresponding $p$-value is lower than 0.05 . 

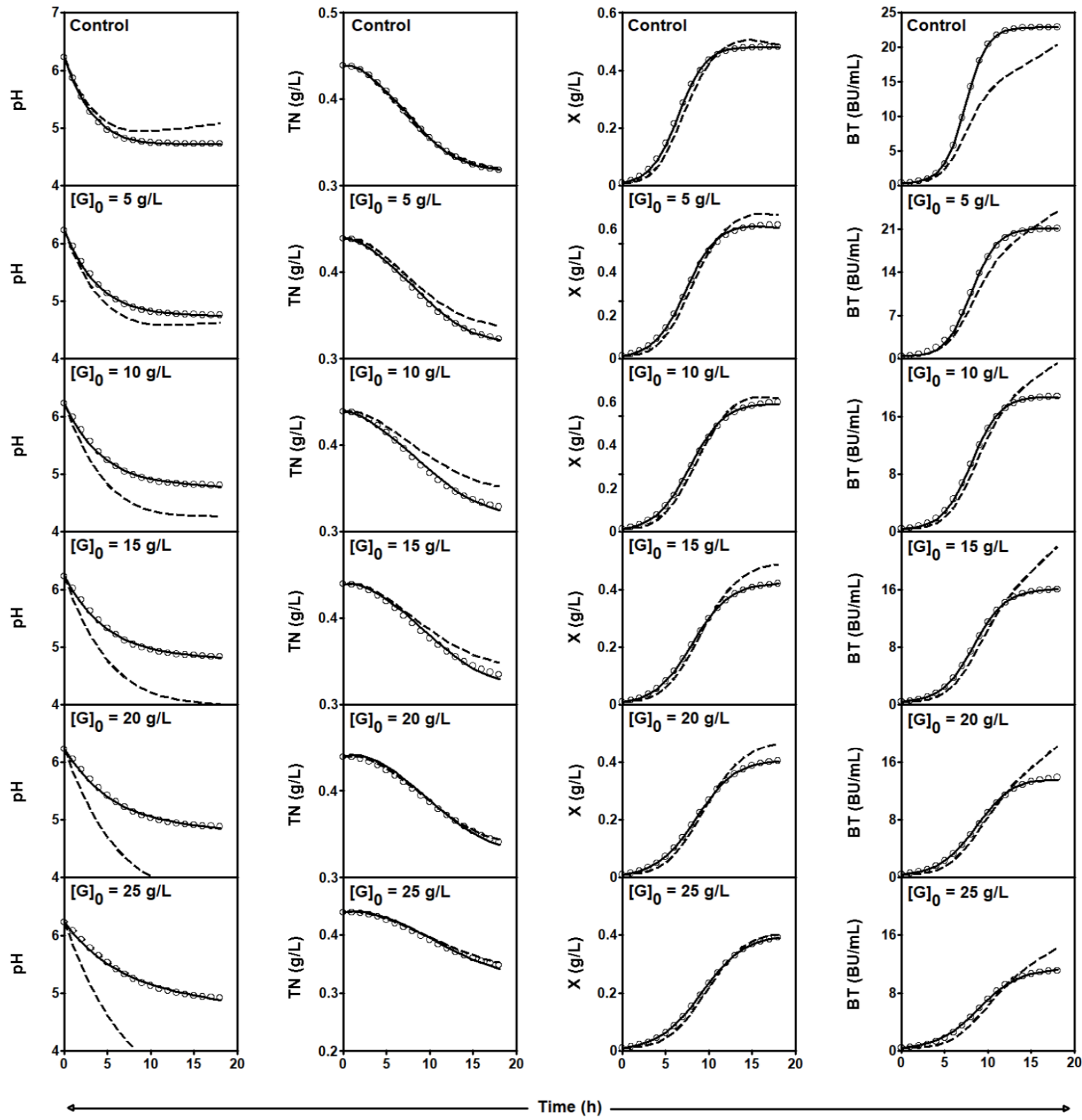

Figure 1. Experimental data (symbols) of culture $\mathrm{pH}, \mathrm{TN}$ consumption, and $\mathrm{X}$ and Nis synthesis by L. lactis CECT 539 in batch fermentations in DW medium supplemented with different glucose levels $\left([G]_{0}\right)$. Dashed lines drawn through the experimental data are predictions of the global fourdimensional predator-prey system (1)-(4) obtained with the parameters shown in Table 3. Solid lines were obtained by adjusting the four-dimensional predator-prey system to the experimental data corresponding to each individual culture (see parameter values in Table 4). Reproduced with permission from Costas et al. [16], Appl. Microbiol. Biotechnol.; published by Springer Nature, 2016. 
Table 4. Statistically significant $(p<0.05)$ parameter values (as estimates \pm confidence intervals) calculated with the four-dimensional predator-prey system (1)-(4) for each individual culture of the series of fermentation DW-G.

\begin{tabular}{|c|c|c|c|c|c|c|}
\hline \multirow[b]{2}{*}{ Parameter } & \multicolumn{6}{|c|}{ Initial Glucose Concentrations $(\mathrm{g} / \mathrm{L})$ in the DW Medium } \\
\hline & 0 & 5 & 10 & 15 & 20 & 25 \\
\hline$a$ & $\begin{array}{c}-0.154 \pm 0.003 \\
(p<0.0001)\end{array}$ & $\begin{array}{c}-0.147 \pm 0.001 \\
\quad(p<0.0001)\end{array}$ & $\begin{array}{c}-0.137 \pm 0.002 \\
(p<0.0001)\end{array}$ & $\begin{array}{c}-0.122 \pm 0.001 \\
(p<0.0001)\end{array}$ & $\begin{array}{c}-0.108 \pm 0.004 \\
\quad(p<0.0001)\end{array}$ & $\begin{array}{c}-0.090 \pm 0.003 \\
(p<0.0001)\end{array}$ \\
\hline$b$ & $\begin{array}{c}-0.037 \pm 0.001 \\
(p<0.0001)\end{array}$ & $\begin{array}{c}-0.033 \pm 0.001 \\
(p<0.0001)\end{array}$ & $\begin{array}{c}-0.030 \pm 0.001 \\
(p<0.0001)\end{array}$ & $\begin{array}{c}-0.027 \pm 0.001 \\
(p<0.0001)\end{array}$ & $\begin{array}{c}-0.024 \pm 0.001 \\
(p<0.0001)\end{array}$ & $\begin{array}{c}-0.020 \pm 0.002 \\
(p<0.0001)\end{array}$ \\
\hline$c$ & $\begin{array}{c}0.039 \pm 0.001 \\
(p<0.0001)\end{array}$ & $\begin{array}{c}0.021 \pm 0.001 \\
(p<0.0001)\end{array}$ & $\begin{array}{c}0.014 \pm 0.001 \\
(p<0.0001)\end{array}$ & $\begin{array}{c}0.013 \pm 0.001 \\
(p<0.0001)\end{array}$ & $\begin{array}{c}0.009 \pm 0.001 \\
(p<0.0001)\end{array}$ & $\begin{array}{c}0.002 \pm 0.000 \\
(p<0.0001)\end{array}$ \\
\hline$R_{p H^{2}}$ & 0.9988 & 0.9980 & 0.9973 & 0.9973 & 0.9973 & 0.9968 \\
\hline$R P D M$ & 0.2083 & 0.3362 & 0.4013 & 0.4057 & 0.4107 & 0.4180 \\
\hline$B_{f}$ & 0.9997 & 0.9990 & 0.9988 & 0.9989 & 0.9988 & 0.9993 \\
\hline$A_{f}$ & 1.0021 & 1.0034 & 1.0040 & 1.0041 & 1.0041 & 1.0042 \\
\hline F-ratio & 369.17 & 322.20 & 313.95 & 313.38 & 310.46 & 305.77 \\
\hline$p$-value & $<0.0001$ & $<0.0001$ & $<0.0001$ & $<0.0001$ & $<0.0001$ & $<0.0001$ \\
\hline$d$ & $\begin{array}{c}-0.194 \pm 0.003 \\
(p<0.0001)\end{array}$ & $\begin{array}{c}-0.190 \pm 0.001 \\
(p<0.0001)\end{array}$ & $\begin{array}{c}-0.184 \pm 0.001 \\
(p<0.0001)\end{array}$ & $\begin{array}{c}-0.171 \pm 0.001 \\
(p<0.0001)\end{array}$ & $\begin{array}{c}-0.168 \pm 0.002 \\
(p<0.0001)\end{array}$ & $\begin{array}{c}-0.164 \pm 0.001 \\
(p<0.0001)\end{array}$ \\
\hline$e$ & $\begin{array}{c}-0.909 \pm 0.001 \\
(p<0.0001)\end{array}$ & $\begin{array}{c}-0.899 \pm 0.001 \\
(p<0.0001)\end{array}$ & $\begin{array}{c}-0.884 \pm 0.004 \\
(p<0.0001)\end{array}$ & $\begin{array}{c}-0.851 \pm 0.002 \\
(p<0.0001)\end{array}$ & $\begin{array}{c}-0.846 \pm 0.001 \\
(p<0.0001)\end{array}$ & $\begin{array}{c}-0.836 \pm 0.003 \\
(p<0.0001)\end{array}$ \\
\hline$f$ & $\begin{array}{c}-0.066 \pm 0.002 \\
(p<0.0001)\end{array}$ & $\begin{array}{c}-0.067 \pm 0.005 \\
(p<0.0001)\end{array}$ & $\begin{array}{c}-0.067 \pm 0.003 \\
(p<0.0001)\end{array}$ & $\begin{array}{c}-0.067 \pm 0.002 \\
(p<0.0001)\end{array}$ & $\begin{array}{c}-0.067 \pm 0.001 \\
(p<0.0001)\end{array}$ & $\begin{array}{c}-0.066 \pm 0.002 \\
(p<0.0001)\end{array}$ \\
\hline$g$ & $\begin{array}{c}-0.002 \pm 0.000 \\
(p<0.0001)\end{array}$ & $\begin{array}{c}-0.002 \pm 0.000 \\
(p<0.0001)\end{array}$ & $\begin{array}{c}-0.002 \pm 0.000 \\
(p<0.0001)\end{array}$ & $\begin{array}{c}-0.002 \pm 0.000 \\
(p<0.0001)\end{array}$ & $\begin{array}{c}-0.002 \pm 0.000 \\
(p<0.0001)\end{array}$ & $\begin{array}{c}-0.002 \pm 0.000 \\
(p<0.0001)\end{array}$ \\
\hline$h$ & $\begin{array}{c}0.034 \pm 0.001 \\
(p<0.0001)\end{array}$ & $\begin{array}{c}0.034 \pm 0.001 \\
(p<0.0001)\end{array}$ & $\begin{array}{c}0.033 \pm 0.001 \\
(p<0.0001)\end{array}$ & $\begin{array}{c}0.034 \pm 0.001 \\
(p<0.0001)\end{array}$ & $\begin{array}{c}0.034 \pm 0.001 \\
(p<0.0001)\end{array}$ & $\begin{array}{c}0.034 \pm 0.002 \\
(p<0.0001)\end{array}$ \\
\hline$R_{T N}^{2}$ & 0.9995 & 0.9993 & 0.9987 & 0.9997 & 0.9988 & 0.9998 \\
\hline$R P D M$ & 0.2355 & 0.2260 & 0.3286 & 0.1284 & 0.2986 & 0.0979 \\
\hline$B_{f}$ & 1.0001 & 0.9996 & 0.9994 & 0.9999 & 1.0006 & 1.0002 \\
\hline$A_{f}$ & 1.0024 & 1.0023 & 1.0033 & 1.0013 & 1.0030 & 1.0010 \\
\hline$F$-ratio & 198.79 & 156.66 & 179.35 & 159.14 & 167.55 & 366.64 \\
\hline$p$-value & $<0.0001$ & $<0.0001$ & $<0.0001$ & $<0.0001$ & $<0.0001$ & $<0.0001$ \\
\hline$i$ & $\begin{array}{c}0.843 \pm 0.001 \\
(p<0.0001)\end{array}$ & $\begin{array}{c}0.810 \pm 0.004 \\
(p<0.0001)\end{array}$ & $\begin{array}{c}0.740 \pm 0.001 \\
(p<0.0001)\end{array}$ & $\begin{array}{c}0.626 \pm 0.003 \\
(p<0.0001)\end{array}$ & $\begin{array}{c}0.531 \pm 0.003 \\
(p<0.0001)\end{array}$ & $\begin{array}{c}0.513 \pm 0.000 \\
(p<0.0001)\end{array}$ \\
\hline$j$ & $\begin{array}{c}0.787 \pm 0.016 \\
(p<0.0001)\end{array}$ & $\begin{array}{c}0.787 \pm 0.009 \\
(p<0.0001)\end{array}$ & $\begin{array}{c}0.787 \pm 0.002 \\
(p<0.0001)\end{array}$ & $\begin{array}{c}0.787 \pm 0.008 \\
(p<0.0001)\end{array}$ & $\begin{array}{c}0.787 \pm 0.008 \\
(p<0.0001)\end{array}$ & $\begin{array}{c}0.787 \pm 0.001 \\
(p<0.0001)\end{array}$ \\
\hline$k$ & $\begin{array}{c}0.008 \pm 0.001 \\
(p<0.0001)\end{array}$ & $\begin{array}{c}0.008 \pm 0.000 \\
(p<0.0001)\end{array}$ & $\begin{array}{c}0.008 \pm 0.001 \\
(p<0.0001)\end{array}$ & $\begin{array}{c}0.008 \pm 0.001 \\
(p<0.0001)\end{array}$ & $\begin{array}{c}0.008 \pm 0.001 \\
(p<0.0001)\end{array}$ & $\begin{array}{c}0.008 \pm 0.001 \\
(p<0.0001)\end{array}$ \\
\hline$l$ & $\begin{array}{c}0.066 \pm 0.003 \\
(p<0.0001)\end{array}$ & $\begin{array}{c}0.065 \pm 0.001 \\
(p<0.0001)\end{array}$ & $\begin{array}{c}0.056 \pm 0.002 \\
(p<0.0001)\end{array}$ & $\begin{array}{c}0.040 \pm 0.001 \\
(p<0.0001)\end{array}$ & $\begin{array}{c}0.026 \pm 0.000 \\
(p<0.0001)\end{array}$ & $\begin{array}{c}0.026 \pm 0.001 \\
(p<0.0001)\end{array}$ \\
\hline$m$ & $\begin{array}{c}-0.104 \pm 0.012 \\
(p<0.0001)\end{array}$ & $\begin{array}{c}-0.103 \pm 0.007 \\
(p<0.0001)\end{array}$ & $\begin{array}{c}-0.102 \pm 0.012 \\
(p<0.0001)\end{array}$ & $\begin{array}{c}-0.101 \pm 0.001 \\
(p<0.0001)\end{array}$ & $\begin{array}{c}-0.092 \pm 0.001 \\
(p<0.0001)\end{array}$ & $\begin{array}{c}-0.079 \pm 0.001 \\
(p<0.0001)\end{array}$ \\
\hline$R_{X}^{2}$ & 0.9997 & 0.9990 & 0.9991 & 1.0000 & 1.0000 & 1.0000 \\
\hline$R P D M$ & 2.6773 & 2.1414 & 1.6724 & 0.9334 & 0.6215 & 0.4064 \\
\hline$B_{f}$ & 0.9764 & 0.9952 & 1.0056 & 0.9937 & 0.9962 & 1.0005 \\
\hline$A_{f}$ & 1.0282 & 1.0218 & 1.0168 & 1.0095 & 1.0063 & 1.0041 \\
\hline$F$-ratio & 163893.47 & 158803.25 & 165456.52 & 169736.76 & 179962.55 & 18968.82 \\
\hline$p$-value & $<0.0001$ & $<0.0001$ & $<0.0001$ & $<0.0001$ & $<0.0001$ & $<0.0001$ \\
\hline$n$ & $\begin{array}{c}3.727 \pm 0.015 \\
(p<0.0001)\end{array}$ & $\begin{array}{c}3.664 \pm 0.016 \\
(p<0.0001)\end{array}$ & $\begin{array}{c}2.672 \pm 0.033 \\
(p<0.0001)\end{array}$ & $\begin{array}{c}1.939 \pm 0.022 \\
(p<0.0001)\end{array}$ & $\begin{array}{c}1.496 \pm 0.016 \\
(p<0.0001)\end{array}$ & $\begin{array}{c}0.922 \pm 0.005 \\
(p<0.0001)\end{array}$ \\
\hline$o$ & $\begin{array}{c}0.036 \pm 0.002 \\
(p<0.0001)\end{array}$ & $\begin{array}{c}0.036 \pm 0.001 \\
(p<0.0001)\end{array}$ & $\begin{array}{c}0.036 \pm 0.004 \\
(p<0.0001)\end{array}$ & $\begin{array}{c}0.036 \pm 0.003 \\
(p<0.0001)\end{array}$ & $\begin{array}{c}0.036 \pm 0.003 \\
(p<0.0001)\end{array}$ & $\begin{array}{c}0.036 \pm 0.002 \\
(p<0.0001)\end{array}$ \\
\hline$p$ & $\begin{array}{c}0.137 \pm 0.006 \\
(p<0.0001)\end{array}$ & $\begin{array}{c}0.137 \pm 0.004 \\
(p<0.0001)\end{array}$ & $\begin{array}{c}0.137 \pm 0.022 \\
(p<0.0001)\end{array}$ & $\begin{array}{c}0.137 \pm 0.011 \\
(p<0.0001)\end{array}$ & $\begin{array}{c}0.137 \pm 0.010 \\
(p<0.0001)\end{array}$ & $\begin{array}{c}0.137 \pm 0.002 \\
(p<0.0001)\end{array}$ \\
\hline$q$ & $\begin{array}{c}0.607 \pm 0.013 \\
(p<0.0001)\end{array}$ & $\begin{array}{c}0.605 \pm 0.009 \\
(p<0.0001)\end{array}$ & $\begin{array}{c}0.409 \pm 0.003 \\
(p<0.0001)\end{array}$ & $\begin{array}{c}0.276 \pm 0.002 \\
(p<0.0001)\end{array}$ & $\begin{array}{c}0.201 \pm 0.021 \\
(p<0.0001)\end{array}$ & $\begin{array}{c}0.100 \pm 0.001 \\
(p<0.0001)\end{array}$ \\
\hline$r$ & $\begin{array}{c}-0.092 \pm 0.003 \\
(p<0.0001)\end{array}$ & $\begin{array}{c}-0.092 \pm 0.002 \\
(p<0.0001)\end{array}$ & $\begin{array}{c}-0.092 \pm 0.002 \\
(p<0.0001)\end{array}$ & $\begin{array}{c}-0.092 \pm 0.001 \\
(p<0.0001)\end{array}$ & $\begin{array}{c}-0.092 \pm 0.004 \\
(p<0.0001)\end{array}$ & $\begin{array}{c}-0.092 \pm 0.001 \\
(p<0.0001)\end{array}$ \\
\hline$R_{B T^{2}}$ & 1.0000 & 0.9997 & 0.9998 & 1.0000 & 0.9992 & 0.9997 \\
\hline$R P D M$ & 0.7956 & 7.5772 & 2.8486 & 0.5489 & 1.2762 & 4.3632 \\
\hline$B_{f}$ & 0.9953 & 0.9232 & 0.9748 & 1.0042 & 0.9997 & 1.0365 \\
\hline$A_{f}$ & 1.0082 & 1.0894 & 1.0300 & 1.0054 & 1.0124 & 1.0423 \\
\hline$F$-ratio & 16623.57 & 14125.66 & 14185.31 & 16845.44 & 9845.37 & 14054.20 \\
\hline$p$-value & $<0.0001$ & $<0.0001$ & $<0.0001$ & $<0.0001$ & $<0.0001$ & $<0.0001$ \\
\hline
\end{tabular}



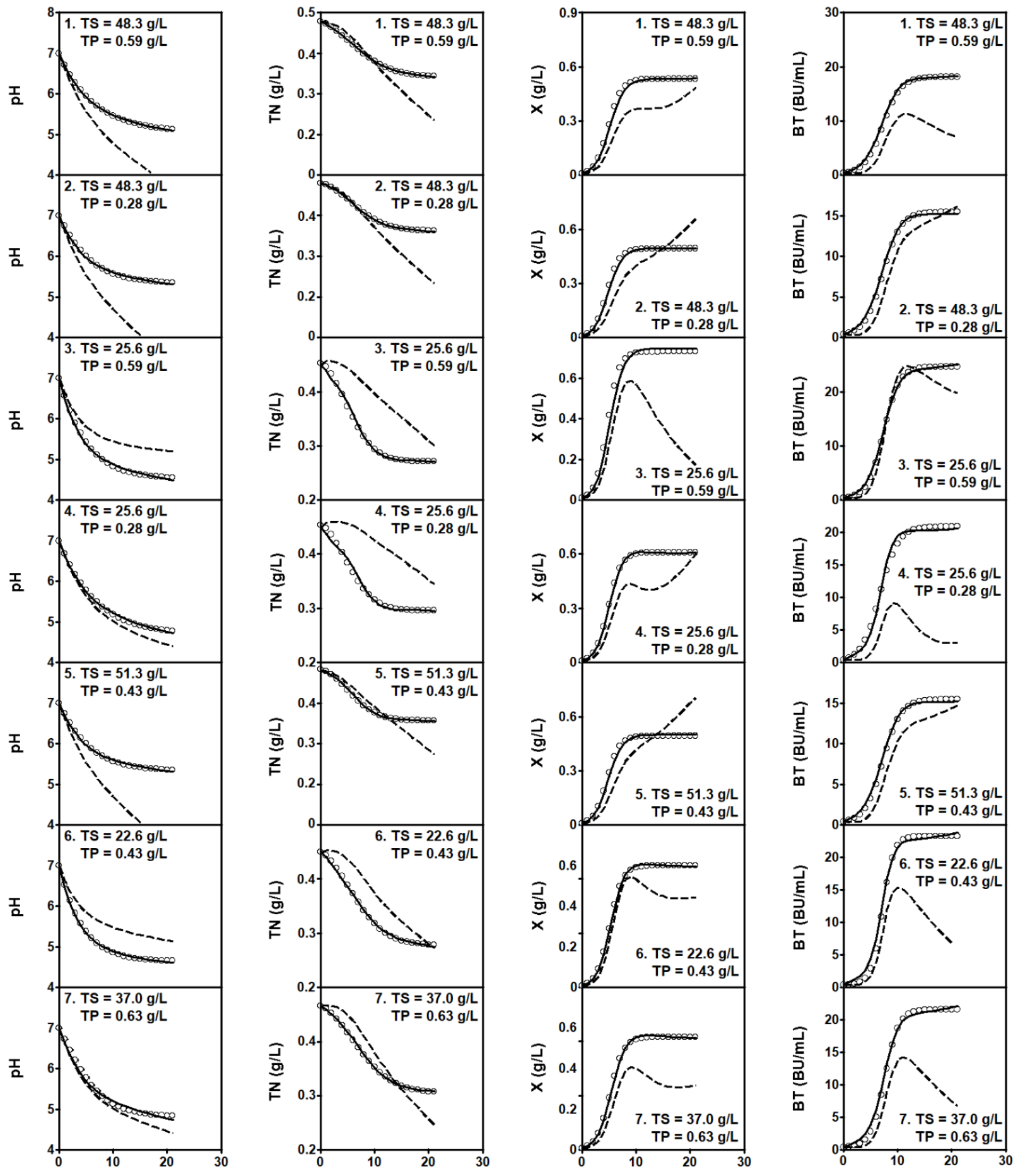

Time (h)

Figure 2. Experimental data (symbols) of culture $\mathrm{pH}$, TN consumption, and $\mathrm{X}$ and Nis production by L. lactis CECT 539 in the first seven batch cultures of the experimental matrix (Table 2), corresponding to the fermentation series DW-TS-TP. Dashed lines drawn through the experimental data are predictions of the global four-dimensional predator-prey systems (1)-(4) obtained with the parameters shown in Table 3. Solid lines were obtained by adjusting the four-dimensional predator-prey system (1)-(4) to the experimental data corresponding to each individual culture (see parameter values in Table 5). Reproduced with permission from Costas et al. [17], 3-Biotech; published by Springer Nature, 2018. 
Table 5. Statistically significant $(p<0.05)$ parameter values (as estimates \pm confidence intervals) calculated with the four-dimensional predator-prey system (1)-(4) for each individual culture corresponding to the four factorial points and the four axial points of the experimental matrix (Table 2) of the series of fermentation DW-TS-TP.

\begin{tabular}{|c|c|c|c|c|c|c|c|c|}
\hline \multirow[b]{2}{*}{ Parameter } & \multicolumn{4}{|c|}{ Factorial Points } & \multicolumn{4}{|c|}{ Axial Points } \\
\hline & $\begin{array}{l}\mathrm{TS}=48.3 \mathrm{~g} / \mathrm{L} \\
\mathrm{TP}=0.59 \mathrm{~g} / \mathrm{L}\end{array}$ & $\begin{array}{l}\mathrm{TS}=48.3 \mathrm{~g} / \mathrm{L} \\
\mathrm{TP}=0.28 \mathrm{~g} / \mathrm{L}\end{array}$ & $\begin{array}{l}\mathrm{TS}=25.6 \mathrm{~g} / \mathrm{L} \\
\mathrm{TP}=0.59 \mathrm{~g} / \mathrm{L}\end{array}$ & $\begin{array}{l}\mathrm{TS}=25.6 \mathrm{~g} / \mathrm{L} \\
\mathrm{TP}=0.28 \mathrm{~g} / \mathrm{L}\end{array}$ & $\begin{array}{l}\mathrm{TS}=51.3 \mathrm{~g} / \mathrm{L} \\
\mathrm{TP}=0.43 \mathrm{~g} / \mathrm{L}\end{array}$ & $\begin{array}{l}\mathrm{TS}=22.6 \mathrm{~g} / \mathrm{L} \\
\mathrm{TP}=0.43 \mathrm{~g} / \mathrm{L}\end{array}$ & $\begin{array}{l}\mathrm{TS}=37.0 \mathrm{~g} / \mathrm{L} \\
\mathrm{TP}=0.63 \mathrm{~g} / \mathrm{L}\end{array}$ & $\begin{array}{l}\mathrm{TS}=37.0 \mathrm{~g} / \mathrm{L} \\
\mathrm{TP}=0.24 \mathrm{~g} / \mathrm{L}\end{array}$ \\
\hline$a$ & $\begin{array}{c}-0.009 \pm 0.001 \\
(p<0.0001)\end{array}$ & $\begin{array}{c}-0.008 \pm 0.011 \\
(p<0.0001)\end{array}$ & $\begin{array}{c}-0.015 \pm 0.002 \\
(p<0.0001)\end{array}$ & $\begin{array}{c}-0.013 \pm 0.001 \\
(p<0.0001)\end{array}$ & $\begin{array}{c}-0.008 \pm 0.001 \\
(p<0.0001)\end{array}$ & $\begin{array}{c}-0.014 \pm 0.001 \\
(p<0.0001)\end{array}$ & $\begin{array}{c}-0.012 \pm 0.001 \\
(p<0.0001)\end{array}$ & $\begin{array}{c}-0.011 \pm 0.002 \\
(p<0.0001)\end{array}$ \\
\hline$b$ & $\begin{array}{c}-0.007 \pm 0.002 \\
(p<0.0001)\end{array}$ & $\begin{array}{c}-0.007 \pm 0.002 \\
(p<0.0001)\end{array}$ & $\begin{array}{c}-0.012 \pm 0.003 \\
(p<0.0001)\end{array}$ & $\begin{array}{c}-0.009 \pm 0.001 \\
(p<0.0001)\end{array}$ & $\begin{array}{c}-0.007 \pm 0.001 \\
(p<0.0001)\end{array}$ & $\begin{array}{c}-0.012 \pm 0.001 \\
(p<0.0001)\end{array}$ & $\begin{array}{c}-0.009 \pm 0.002 \\
(p<0.0001)\end{array}$ & $\begin{array}{c}-0.008 \pm 0.002 \\
(p<0.0001)\end{array}$ \\
\hline$c$ & $\begin{array}{c}0.041 \pm 0.003 \\
(p<0.0001)\end{array}$ & $\begin{array}{c}0.050 \pm 0.011 \\
(p<0.0001)\end{array}$ & $\begin{array}{c}0.045 \pm 0.005 \\
(p<0.0001)\end{array}$ & $\begin{array}{c}0.034 \pm 0.000 \\
(p<0.0001)\end{array}$ & $\begin{array}{c}0.050 \pm 0.000 \\
(p<0.0001)\end{array}$ & $\begin{array}{c}0.057 \pm 0.004 \\
(p<0.0001)\end{array}$ & $\begin{array}{c}0.036 \pm 0.001 \\
(p<0.0001)\end{array}$ & $\begin{array}{c}0.043 \pm 0.002 \\
(p<0.0001)\end{array}$ \\
\hline$R_{p H^{2}}$ & 0.9961 & 0.9918 & 0.9941 & 0.9952 & 0.9918 & 0.9971 & 0.9897 & 0.9903 \\
\hline$R P D M$ & 0.5322 & 0.6954 & 0.9820 & 0.7802 & 0.6954 & 0.6045 & 1.1740 & 0.9703 \\
\hline$B_{f}$ & 0.9997 & 0.9995 & 0.9994 & 0.9994 & 0.9995 & 0.9999 & 0.9988 & 0.9990 \\
\hline$A_{f}$ & 1.0053 & 1.0070 & 1.0099 & 1.0078 & 1.0070 & 1.0061 & 1.0118 & 1.0098 \\
\hline$F$-ratio & 1225.62 & 1502.17 & 1414.37 & 1203.42 & 1203.42 & 588.82 & 1308.83 & 698.32 \\
\hline$p$-value & $<0.0001$ & $<0.0001$ & $<0.0001$ & $<0.0001$ & $<0.0001$ & $<0.0001$ & $<0.0001$ & $<0.0001$ \\
\hline$d$ & $\begin{array}{c}-0.188 \pm 0.023 \\
(p<0.0001)\end{array}$ & $\begin{array}{c}-0.209 \pm 0.016 \\
(p<0.0001)\end{array}$ & $\begin{array}{c}-0.595 \pm 0.029 \\
(p<0.0001)\end{array}$ & $\begin{array}{c}-0.741 \pm 0.026 \\
(p<0.0001)\end{array}$ & $\begin{array}{c}-0.453 \pm 0.023 \\
(p<0.0001)\end{array}$ & $\begin{array}{c}-0.154 \pm 0.002 \\
(p<0.0001)\end{array}$ & $\begin{array}{c}-0.196 \pm 0.007 \\
(p<0.0001)\end{array}$ & $\begin{array}{c}-0.170 \pm 0.008 \\
(p<0.0001)\end{array}$ \\
\hline$e$ & $\begin{array}{c}-0.914 \pm 0.037 \\
(p<0.0001)\end{array}$ & $\begin{array}{c}-0.940 \pm 0.022 \\
(p<0.0001)\end{array}$ & $\begin{array}{c}-1.897 \pm 0.088 \\
(p<0.0001)\end{array}$ & $\begin{array}{c}-2.224 \pm 0.101 \\
(p=0.0103)\end{array}$ & $\begin{array}{c}-1.447 \pm 0.066 \\
(p<0.0001)\end{array}$ & $\begin{array}{c}-0.903 \pm 0.016 \\
(p<0.0001)\end{array}$ & $\begin{array}{c}-0.955 \pm 0.021 \\
(p<0.0001)\end{array}$ & $\begin{array}{c}-0.885 \pm 0.013 \\
(p<0.0001)\end{array}$ \\
\hline$f$ & $\begin{array}{c}-0.058 \pm 0.002 \\
(p<0.0001)\end{array}$ & $\begin{array}{c}-0.073 \pm 0.006 \\
(p<0.0001)\end{array}$ & $\begin{array}{c}-0.288 \pm 0.013 \\
(p<0.0001)\end{array}$ & $\begin{array}{c}-0.368 \pm 0.019 \\
(p<0.0001)\end{array}$ & $\begin{array}{c}-0.206 \pm 0.018 \\
(p<0.0001)\end{array}$ & $\begin{array}{c}-0.058 \pm 0.002 \\
(p<0.0001)\end{array}$ & $\begin{array}{c}-0.073 \pm 0.001 \\
(p<0.0001)\end{array}$ & $\begin{array}{c}-0.073 \pm 0.003 \\
(p<0.0001)\end{array}$ \\
\hline$g$ & $\begin{array}{c}-0.001 \pm 0.000 \\
(p=0.0012)\end{array}$ & $\begin{array}{c}-0.001 \pm 0.000 \\
(p=0.0025)\end{array}$ & $\begin{array}{c}-0.001 \pm 0.000 \\
(p<0.0001)\end{array}$ & $\begin{array}{c}-0.001 \pm 0.000 \\
(p=0.0024)\end{array}$ & $\begin{array}{c}-0.001 \pm 0.000 \\
(p<0.0001)\end{array}$ & $\begin{array}{c}-0.001 \pm 0.000 \\
(p<0.0001)\end{array}$ & $\begin{array}{c}-0.001 \pm 0.000 \\
(p<0.0001)\end{array}$ & $\begin{array}{c}-0.001 \pm 0.000 \\
(p<0.0001)\end{array}$ \\
\hline$h$ & $\begin{array}{c}0.034 \pm 0.002 \\
(p<0.0001)\end{array}$ & $\begin{array}{c}0.034 \pm 0.007 \\
(p<0.0001)\end{array}$ & $\begin{array}{c}0.034 \pm 0.004 \\
(p<0.0001)\end{array}$ & $\begin{array}{c}0.034 \pm 0.003 \\
(p<0.0001)\end{array}$ & $\begin{array}{c}0.034 \pm 0.002 \\
(p<0.0001)\end{array}$ & $\begin{array}{c}0.034 \pm 0.004 \\
(p<0.0001)\end{array}$ & $\begin{array}{c}0.034 \pm 0.003 \\
(p<0.0001)\end{array}$ & $\begin{array}{c}0.034 \pm 0.002 \\
(p<0.0001)\end{array}$ \\
\hline$R_{T N}^{2}$ & 0.9998 & 0.9996 & 0.9974 & 0.9947 & 0.9987 & 0.9987 & 0.9995 & 0.9973 \\
\hline$R P D M$ & 0.1460 & 0.1608 & 0.5997 & 0.7355 & 0.2837 & 0.6074 & 0.2451 & 0.7085 \\
\hline$B_{f}$ & 1.0000 & 1.0002 & 0.9992 & 0.9995 & 1.0002 & 0.9992 & 0.9998 & 0.9989 \\
\hline$A_{f}$ & 1.0015 & 1.0016 & 1.0060 & 1.0074 & 1.0028 & 1.0061 & 1.0025 & 1.0071 \\
\hline$F$-ratio & 111.24 & 136.45 & 128.63 & 145.52 & 809.54 & 101.89 & 99.51 & 221.34 \\
\hline$p$-value & $<0.0001$ & $<0.0001$ & $<0.0001$ & $<0.0001$ & $<0.0001$ & $<0.0001$ & $<0.0001$ & $<0.0001$ \\
\hline$i$ & $\begin{array}{c}0.805 \pm 0.027 \\
(p<0.0001)\end{array}$ & $\begin{array}{c}0.781 \pm 0.011 \\
(p<0.0001)\end{array}$ & $\begin{array}{c}0.923 \pm 0.026 \\
(p<0.0001)\end{array}$ & $\begin{array}{c}0.940 \pm 0.005 \\
(p<0.0001)\end{array}$ & $\begin{array}{c}0.845 \pm 0.019 \\
(p<0.0001)\end{array}$ & $\begin{array}{c}0.978 \pm 0.027 \\
(p<0.0001)\end{array}$ & $\begin{array}{c}0.860 \pm 0.027 \\
(p<0.0001)\end{array}$ & $\begin{array}{c}0.823 \pm 0.016 \\
(p<0.0001)\end{array}$ \\
\hline$j$ & $\begin{array}{c}1.172 \pm 0.084 \\
(p<0.0001)\end{array}$ & $\begin{array}{c}1.319 \pm 0.025 \\
(p<0.0001)\end{array}$ & $\begin{array}{c}0.884 \pm 0.010 \\
(p<0.0001)\end{array}$ & $\begin{array}{c}1.127 \pm 0.014 \\
(p<0.0001)\end{array}$ & $\begin{array}{c}1.349 \pm 0.103 \\
(p<0.0001)\end{array}$ & $\begin{array}{c}0.967 \pm 0.010 \\
(p<0.0001)\end{array}$ & $\begin{array}{c}0.973 \pm 0.025 \\
(p<0.0001)\end{array}$ & $\begin{array}{c}1.098 \pm 0.103 \\
(p<0.0001)\end{array}$ \\
\hline$k$ & $\begin{array}{c}0.005 \pm 0.001 \\
(p<0.0001)\end{array}$ & $\begin{array}{c}0.005 \pm 0.000 \\
(p<0.0001)\end{array}$ & $\begin{array}{c}0.005 \pm 0.000 \\
(p<0.0001)\end{array}$ & $\begin{array}{c}0.005 \pm 0.000 \\
(p=0.0012)\end{array}$ & $\begin{array}{c}0.005 \pm 0.000 \\
(p<0.0001)\end{array}$ & $\begin{array}{c}0.005 \pm 0.000 \\
(p<0.0001)\end{array}$ & $\begin{array}{c}0.005 \pm 0.000 \\
(p=0.0012)\end{array}$ & $\begin{array}{c}0.005 \pm 0.000 \\
(p<0.0001)\end{array}$ \\
\hline$l$ & $\begin{array}{c}0.017 \pm 0.001 \\
(p<0.0001)\end{array}$ & $\begin{array}{c}0.009 \pm 0.001 \\
(p<0.0001)\end{array}$ & $\begin{array}{c}0.033 \pm 0.002 \\
(p<0.0001)\end{array}$ & $\begin{array}{c}0.030 \pm 0.002 \\
(p<0.0001)\end{array}$ & $\begin{array}{c}0.018 \pm 0.001 \\
(p<0.0001)\end{array}$ & $\begin{array}{c}0.044 \pm 0.003 \\
(p<0.0001)\end{array}$ & $\begin{array}{c}0.029 \pm 0.001 \\
(p<0.0001)\end{array}$ & $\begin{array}{c}0.024 \pm 0.002 \\
(p<0.0001)\end{array}$ \\
\hline$m$ & $\begin{array}{c}-0.002 \pm 0.000 \\
(p<0.0001)\end{array}$ & $\begin{array}{c}-0.002 \pm 0.001 \\
(p<0.0001)\end{array}$ & $\begin{array}{c}-0.002 \pm 0.000 \\
(p<0.0001)\end{array}$ & $\begin{array}{c}-0.002 \pm 0.000 \\
(p<0.0001)\end{array}$ & $\begin{array}{c}-0.002 \pm 0.001 \\
(p<0.0001)\end{array}$ & $\begin{array}{c}-0.002 \pm 0.002 \\
(p<0.0001)\end{array}$ & $\begin{array}{c}-0.002 \pm 0.001 \\
(p<0.0001)\end{array}$ & $\begin{array}{c}-0.002 \pm 0.001 \\
(p<0.0001)\end{array}$ \\
\hline$R_{X}^{2}$ & 0.9973 & 0.9958 & 0.9939 & 0.9989 & 0.9965 & 0.9992 & 0.9983 & 0.9984 \\
\hline$R P D M$ & 3.2062 & 3.5977 & 4.8630 & 2.0830 & 3.3137 & 2.4733 & 3.0536 & 2.8520 \\
\hline$B_{f}$ & 0.9797 & 0.9788 & 0.9680 & 0.9802 & 0.9796 & 0.9816 & 0.9778 & 0.9794 \\
\hline$A_{f}$ & 1.0336 & 1.0378 & 1.0525 & 1.0215 & 1.0347 & 1.0259 & 1.0321 & 1.0299 \\
\hline$F$-ratio & 2655.11 & 2222.57 & 2246.34 & 18756.55 & 11253.26 & 36008.93 & 5001.64 & 4953.73 \\
\hline$p$-value & $<0.0001$ & $<0.0001$ & $<0.0001$ & $<0.0001$ & $<0.0001$ & $<0.0001$ & $<0.0001$ & $<0.0001$ \\
\hline$n$ & $\begin{array}{c}1.068 \pm 0.018 \\
(p<0.0001)\end{array}$ & $\begin{array}{c}1.066 \pm 0.009 \\
(p<0.0001)\end{array}$ & $\begin{array}{c}1.314 \pm 0.015 \\
(p<0.0001)\end{array}$ & $\begin{array}{c}1.136 \pm 0.086 \\
(p<0.0001)\end{array}$ & $\begin{array}{c}1.067 \pm 0.043 \\
(p<0.0001)\end{array}$ & $\begin{array}{c}1.226 \pm 0.111 \\
(p<0.0001)\end{array}$ & $\begin{array}{c}1.136 \pm 0.044 \\
(p<0.0001)\end{array}$ & $\begin{array}{c}1.071 \pm 0.003 \\
(p<0.0001)\end{array}$ \\
\hline$o$ & $\begin{array}{c}0.035 \pm 0.003 \\
(p<0.0001)\end{array}$ & $\begin{array}{c}0.040 \pm 0.003 \\
(p<0.0001)\end{array}$ & $\begin{array}{c}0.030 \pm 0.001 \\
(p<0.0001)\end{array}$ & $\begin{array}{c}0.033 \pm 0.002 \\
(p<0.0001)\end{array}$ & $\begin{array}{c}0.040 \pm 0.005 \\
(p<0.0001)\end{array}$ & $\begin{array}{c}0.036 \pm 0.001 \\
(p<0.0001)\end{array}$ & $\begin{array}{c}0.036 \pm 0.001 \\
(p<0.0001)\end{array}$ & $\begin{array}{c}0.037 \pm 0.002 \\
(p<0.0001)\end{array}$ \\
\hline$p$ & $\begin{array}{c}0.098 \pm 0.010 \\
(p<0.0001)\end{array}$ & $\begin{array}{c}0.098 \pm 0.006 \\
(p<0.0001)\end{array}$ & $\begin{array}{c}0.098 \pm 0.002 \\
(p<0.0001)\end{array}$ & $\begin{array}{c}0.098 \pm 0.006 \\
(p<0.0001)\end{array}$ & $\begin{array}{c}0.098 \pm 0.004 \\
(p<0.0001)\end{array}$ & $\begin{array}{c}0.098 \pm 0.005 \\
(p<0.0001)\end{array}$ & $\begin{array}{c}0.098 \pm 0.006 \\
(p<0.0001)\end{array}$ & $\begin{array}{c}0.098 \pm 0.001 \\
(p<0.0001)\end{array}$ \\
\hline$q$ & $\begin{array}{c}0.080 \pm 0.005 \\
(p<0.0001)\end{array}$ & $\begin{array}{c}0.081 \pm 0.002 \\
(p<0.0001)\end{array}$ & $\begin{array}{c}0.117 \pm 0.001 \\
(p<0.0001)\end{array}$ & $\begin{array}{c}0.086 \pm 0.002 \\
(p<0.0001)\end{array}$ & $\begin{array}{c}0.081 \pm 0.002 \\
(p<0.0001)\end{array}$ & $\begin{array}{c}0.073 \pm 0.004 \\
(p<0.0001)\end{array}$ & $\begin{array}{c}0.073 \pm 0.002 \\
(p<0.0001)\end{array}$ & $\begin{array}{c}0.073 \pm 0.006 \\
(p<0.0001)\end{array}$ \\
\hline$r$ & $\begin{array}{c}-0.103 \pm 0.008 \\
(p<0.0001)\end{array}$ & $\begin{array}{c}-0.103 \pm 0.003 \\
(p<0.0001)\end{array}$ & $\begin{array}{c}-0.309 \pm 0.018 \\
(p<0.0001)\end{array}$ & $\begin{array}{c}-0.103 \pm 0.008 \\
(p<0.0001)\end{array}$ & $\begin{array}{c}-0.103 \pm 0.003 \\
(p<0.0001)\end{array}$ & $\begin{array}{c}-0.103 \pm 0.008 \\
(p<0.0001)\end{array}$ & $\begin{array}{c}-0.103 \pm 0.003 \\
(p<0.0001)\end{array}$ & $\begin{array}{c}-0.103 \pm 0.009 \\
(p<0.0001)\end{array}$ \\
\hline$R_{B T^{2}}$ & 0.9988 & 0.9983 & 0.9988 & 0.9971 & 0.9987 & 0.9982 & 0.9983 & 0.9983 \\
\hline$R P D M$ & 6.2540 & 7.5243 & 7.4690 & 4.1038 & 7.3319 & 21.2434 & 16.3565 & 14.6312 \\
\hline$B_{f}$ & 1.0562 & 1.0597 & 1.0602 & 1.0275 & 1.0653 & 1.1581 & 1.1369 & 1.1155 \\
\hline$A_{f}$ & 1.0596 & 1.0714 & 1.0702 & 1.0406 & 1.0691 & 1.1700 & 1.1398 & 1.1272 \\
\hline$F$-ratio & 15333.43 & 15698.19 & 6008.51 & 9253.62 & 57045.82 & 11115.87 & 12489.56 & 13001.43 \\
\hline$p$-value & $<0.0001$ & $<0.0001$ & $<0.0001$ & $<0.0001$ & $<0.0001$ & $<0.0001$ & $<0.0001$ & $<0.0001$ \\
\hline
\end{tabular}

The parameter value is considered statistically significant if its corresponding $p$-value is lower than 0.05 . 

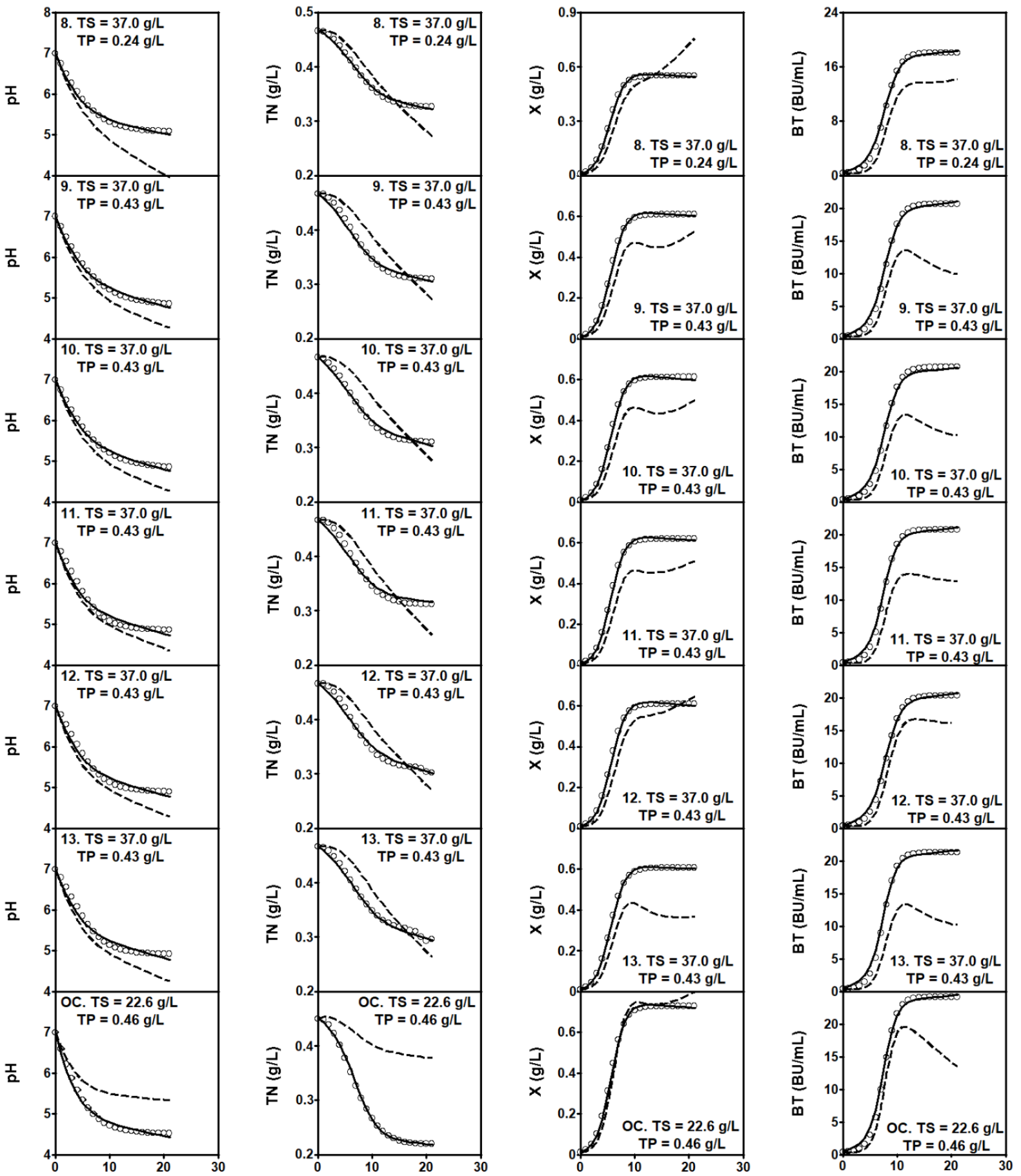

Time (h)

Figure 3. Experimental data (symbols) of culture $\mathrm{pH}$, TN consumption, and $\mathrm{X}$ and Nis production by L. lactis CECT 539 in the last six batch cultures of the experimental matrix (Table 2) and in the optimum conditions (OC), corresponding to the fermentation series DW-TS-TP. Dashed lines drawn through the experimental data are predictions of the global four-dimensional predator-prey system (1)-(4) obtained with the parameters shown in Table 3. Solid lines were obtained by adjusting the fourdimensional predator-prey system (1)-(4) to the experimental data corresponding to each individual culture (see parameter values in Tables 5 and 6). Reproduced with permission from Costas et al. [17], 3-Biotech; published by Springer Nature, 2018. 
Table 6. Statistically significant $(p<0.05)$ parameter values (as estimates \pm confidence intervals) calculated with the four-dimensional predator-prey system (1)-(4) for each individual culture corresponding to the five center points (TS $=37.0 \mathrm{~g} / \mathrm{L}, \mathrm{TP}=0.43 \mathrm{~g} / \mathrm{L}$ ) of the experimental matrix (Table 2) and to the optimum conditions (TS $=22.6 \mathrm{~g} / \mathrm{L}, \mathrm{TP}=0.46 \mathrm{~g} / \mathrm{L}$ ) of the series of fermentation DW-TS-TP.

\begin{tabular}{|c|c|c|c|c|c|c|}
\hline & & & Center Points & & & $\begin{array}{l}\text { Optimum } \\
\text { Conditions }\end{array}$ \\
\hline Parameter & $\begin{array}{l}\mathrm{TS}=37.0 \mathrm{~g} / \mathrm{L} \\
\mathrm{TP}=0.43 \mathrm{~g} / \mathrm{L}\end{array}$ & $\begin{array}{l}\mathrm{TS}=37.0 \mathrm{~g} / \mathrm{L} \\
\mathrm{TP}=0.43 \mathrm{~g} / \mathrm{L}\end{array}$ & $\begin{array}{l}\mathrm{TS}=37.0 \mathrm{~g} / \mathrm{L} \\
\mathrm{TP}=0.43 \mathrm{~g} / \mathrm{L}\end{array}$ & $\begin{array}{l}\mathrm{TS}=37.0 \mathrm{~g} / \mathrm{L} \\
\mathrm{TP}=0.43 \mathrm{~g} / \mathrm{L}\end{array}$ & $\begin{array}{l}\mathrm{TS}=37.0 \mathrm{~g} / \mathrm{L} \\
\mathrm{TP}=0.43 \mathrm{~g} / \mathrm{L}\end{array}$ & $\begin{array}{l}\mathrm{TS}=22.6 \mathrm{~g} / \mathrm{L} \\
\mathrm{TP}=0.46 \mathrm{~g} / \mathrm{L}\end{array}$ \\
\hline$a$ & $\begin{array}{c}-0.012 \pm 0.002 \\
(p<0.0001)\end{array}$ & $\begin{array}{c}-0.012 \pm 0.001 \\
(p<0.0001)\end{array}$ & $\begin{array}{c}-0.012 \pm 0.001 \\
(p<0.0001)\end{array}$ & $\begin{array}{c}-0.012 \pm 0.001 \\
(p<0.0001)\end{array}$ & $\begin{array}{c}-0.012 \pm 0.002 \\
(p<0.0001)\end{array}$ & $\begin{array}{c}-0.016 \pm 0.001 \\
(p<0.0001)\end{array}$ \\
\hline$b$ & $\begin{array}{c}-0.008 \pm 0.001 \\
(p<0.0001)\end{array}$ & $\begin{array}{c}-0.008 \pm 0.003 \\
(p<0.0001)\end{array}$ & $\begin{array}{c}-0.009 \pm 0.001 \\
(p<0.0001)\end{array}$ & $\begin{array}{c}-0.008 \pm 0.002 \\
(p<0.0001)\end{array}$ & $\begin{array}{c}-0.008 \pm 0.001 \\
(p<0.0001)\end{array}$ & $\begin{array}{c}-0.013 \pm 0.001 \\
(p<0.0001)\end{array}$ \\
\hline$c$ & $\begin{array}{c}0.033 \pm 0.004 \\
(p<0.0001)\end{array}$ & $\begin{array}{c}0.033 \pm 0.002 \\
(p<0.0001)\end{array}$ & $\begin{array}{c}0.035 \pm 0.002 \\
(p<0.0001)\end{array}$ & $\begin{array}{c}0.035 \pm 0.002 \\
(p<0.0001)\end{array}$ & $\begin{array}{c}0.035 \pm 0.002 \\
(p<0.0001)\end{array}$ & $\begin{array}{c}0.048 \pm 0.000 \\
(p<0.0001)\end{array}$ \\
\hline$R_{p H}^{2}$ & 0.9903 & 0.9905 & 0.9779 & 0.9805 & 0.9794 & 0.9937 \\
\hline$R P D M$ & 1.1229 & 1.1156 & 1.7516 & 1.6095 & 1.6444 & 1.0972 \\
\hline$B_{f}$ & 0.9988 & 0.9988 & 0.9979 & 0.9980 & 0.9979 & 0.9989 \\
\hline$A_{f}$ & 1.0113 & 1.0112 & 1.0177 & 1.0163 & 1.0166 & 1.0110 \\
\hline$F$-ratio & 1442.53 & 1286.83 & 1399.58 & 1306.41 & 1119.82 & 2610.26 \\
\hline$p$-value & $<0.0001$ & $<0.0001$ & $<0.0001$ & $<0.0001$ & $<0.0001$ & $<0.0001$ \\
\hline$d$ & $\begin{array}{c}-0.168 \pm 0.008 \\
(p<0.0001)\end{array}$ & $\begin{array}{c}-0.174 \pm 0.010 \\
(p<0.0001)\end{array}$ & $\begin{array}{c}-0.196 \pm 0.014 \\
(p<0.0001)\end{array}$ & $\begin{array}{c}-0.169 \pm 0.008 \\
(p<0.0001)\end{array}$ & $\begin{array}{c}-0.168 \pm 0.016 \\
(p<0.0001)\end{array}$ & $\begin{array}{c}-0.472 \pm 0.024 \\
(p<0.0001)\end{array}$ \\
\hline$e$ & $\begin{array}{c}-0.893 \pm 0.013 \\
(p<0.0001)\end{array}$ & $\begin{array}{c}-0.913 \pm 0.004 \\
(p<0.0001)\end{array}$ & $\begin{array}{c}-0.955 \pm 0.010 \\
(p<0.0001)\end{array}$ & $\begin{array}{c}-0.893 \pm 0.016 \\
(p<0.0001)\end{array}$ & $\begin{array}{c}-0.893 \pm 0.055 \\
(p<0.0001)\end{array}$ & $\begin{array}{c}-1.605 \pm 0.102 \\
(p<0.0001)\end{array}$ \\
\hline$f$ & $\begin{array}{c}-0.087 \pm 0.005 \\
(p<0.0001)\end{array}$ & $\begin{array}{c}-0.087 \pm 0.002 \\
(p<0.0001)\end{array}$ & $\begin{array}{c}-0.073 \pm 0.002 \\
(p<0.0001)\end{array}$ & $\begin{array}{c}-0.073 \pm 0.001 \\
(p<0.0001)\end{array}$ & $\begin{array}{c}-0.087 \pm 0.004 \\
(p<0.0001)\end{array}$ & $\begin{array}{c}-0.367 \pm 0.008 \\
(p<0.0001)\end{array}$ \\
\hline$g$ & $\begin{array}{c}-0.001 \pm 0.000 \\
(p<0.0001)\end{array}$ & $\begin{array}{c}-0.001 \pm 0.000 \\
(p<0.0001)\end{array}$ & $\begin{array}{c}-0.001 \pm 0.000 \\
(p<0.0001)\end{array}$ & $\begin{array}{c}-0.001 \pm 0.000 \\
(p<0.0001)\end{array}$ & $\begin{array}{c}-0.001 \pm 0.000 \\
(p<0.0001)\end{array}$ & $\begin{array}{c}-0.001 \pm 0.000 \\
(p<0.0001)\end{array}$ \\
\hline$h$ & $\begin{array}{c}0.034 \pm 0.001 \\
(p<0.0001)\end{array}$ & $\begin{array}{c}0.034 \pm 0.002 \\
(p<0.0001)\end{array}$ & $\begin{array}{c}0.034 \pm 0.001 \\
(p<0.0001)\end{array}$ & $\begin{array}{c}0.034 \pm 0.002 \\
(p<0.0001)\end{array}$ & $\begin{array}{c}0.034 \pm 0.001 \\
(p<0.0001)\end{array}$ & $\begin{array}{c}0.036 \pm 0.003 \\
(p<0.0001)\end{array}$ \\
\hline$R_{T N}^{2}$ & 0.9947 & 0.9933 & 0.9941 & 0.9883 & 0.9941 & 0.9983 \\
\hline RPDM & 1.3103 & 1.2626 & 2.0280 & 1.6987 & 1.6361 & 1.0880 \\
\hline$B_{f}$ & 0.9968 & 0.9982 & 1.0042 & 0.9970 & 0.9835 & 1.0000 \\
\hline$A_{f}$ & 1.0132 & 1.0127 & 1.0205 & 1.0172 & 1.0168 & 1.0109 \\
\hline$F$-ratio & 256.84 & 231.13 & 512.73 & 488.79 & 385.82 & 419.77 \\
\hline$p$-value & $<0.0001$ & $<0.0001$ & $<0.0001$ & $<0.0001$ & $<0.0001$ & $<0.0001$ \\
\hline$i$ & $\begin{array}{c}0.933 \pm 0.017 \\
(p<0.0001)\end{array}$ & $\begin{array}{c}0.932 \pm 0.011 \\
(p<0.0001)\end{array}$ & $\begin{array}{c}0.937 \pm 0.010 \\
(p<0.0001)\end{array}$ & $\begin{array}{c}0.933 \pm 0.006 \\
(p<0.0001)\end{array}$ & $\begin{array}{c}0.936 \pm 0.008 \\
(p<0.0001)\end{array}$ & $\begin{array}{c}0.995 \pm 0.019 \\
(p<0.0001)\end{array}$ \\
\hline$j$ & $\begin{array}{c}1.052 \pm 0.010 \\
(p<0.0001)\end{array}$ & $\begin{array}{c}1.034 \pm 0.00034 \\
(p<0.0001)\end{array}$ & $\begin{array}{c}1.036 \pm 0.022 \\
(p<0.0001)\end{array}$ & $\begin{array}{c}1.048 \pm 0.013 \\
(p<0.0001)\end{array}$ & $\begin{array}{c}1.057 \pm 0.016 \\
(p<0.0001)\end{array}$ & $\begin{array}{c}0.851 \pm 0.008 \\
(p<0.0001)\end{array}$ \\
\hline$k$ & $\begin{array}{c}0.005 \pm 0.001 \\
(p<0.0001)\end{array}$ & $\begin{array}{c}0.005 \pm 0.000 \\
(p<0.0001)\end{array}$ & $\begin{array}{c}0.005 \pm 0.001 \\
(p<0.0001)\end{array}$ & $\begin{array}{c}0.005 \pm 0.001 \\
(p<0.0001)\end{array}$ & $\begin{array}{c}0.005 \pm 0.001 \\
(p<0.0001)\end{array}$ & $\begin{array}{c}0.005 \pm 0.001 \\
(p<0.0001)\end{array}$ \\
\hline$l$ & $\begin{array}{c}0.037 \pm 0.001 \\
(p<0.0001)\end{array}$ & $\begin{array}{c}0.039 \pm 0.001 \\
(p<0.0001)\end{array}$ & $\begin{array}{c}0.038 \pm 0.001 \\
(p<0.0001)\end{array}$ & $\begin{array}{c}0.038 \pm 0.001 \\
(p<0.0001)\end{array}$ & $\begin{array}{c}0.037 \pm 0.001 \\
(p<0.0001)\end{array}$ & $\begin{array}{c}0.055 \pm 0.001 \\
(p<0.0001)\end{array}$ \\
\hline$m$ & $\begin{array}{c}-0.002 \pm 0.000 \\
(p<0.0001)\end{array}$ & $\begin{array}{c}-0.002 \pm 0.001 \\
(p<0.0001)\end{array}$ & $\begin{array}{c}-0.002 \pm 0.001 \\
(p<0.0001)\end{array}$ & $\begin{array}{c}-0.002 \pm 0.000 \\
(p<0.0001)\end{array}$ & $\begin{array}{c}-0.002 \pm 0.001 \\
(p<0.0001)\end{array}$ & $\begin{array}{c}-0.002 \pm 0.001 \\
(p<0.0001)\end{array}$ \\
\hline$R_{X}^{2}$ & 0.9990 & 0.9992 & 0.9993 & 0.9984 & 0.9996 & 0.9993 \\
\hline$R P D M$ & 3.3758 & 2.6198 & 2.1861 & 3.9710 & 3.7304 & 2.5775 \\
\hline$B_{f}$ & 1.0056 & 0.9919 & 0.9786 & 1.0054 & 1.0251 & 0.9767 \\
\hline$A_{f}$ & 1.0344 & 1.0270 & 1.0229 & 1.0406 & 1.0374 & 1.0272 \\
\hline$F$-ratio & 7954.52 & 11136.19 & 24025.14 & 8212.25 & 33154.51 & 27521.83 \\
\hline$p$-value & $<0.0001$ & $<0.0001$ & $<0.0001$ & $<0.0001$ & $<0.0001$ & $<0.0001$ \\
\hline$n$ & $\begin{array}{c}1.136 \pm 0.013 \\
(p<0.0001)\end{array}$ & $\begin{array}{c}1.136 \pm 0.009 \\
(p<0.0001)\end{array}$ & $\begin{array}{c}1.136 \pm 0.010 \\
(p<0.0001)\end{array}$ & $\begin{array}{c}1.136 \pm 0.005 \\
(p<0.0001)\end{array}$ & $\begin{array}{c}1.136 \pm 0.011 \\
(p<0.0001)\end{array}$ & $\begin{array}{c}1.322 \pm 0.007 \\
(p<0.0001)\end{array}$ \\
\hline$o$ & $\begin{array}{c}0.036 \pm 0.001 \\
(p<0.0001)\end{array}$ & $\begin{array}{c}0.036 \pm 0.003 \\
(p<0.0001)\end{array}$ & $\begin{array}{c}0.036 \pm 0.001 \\
(p<0.0001)\end{array}$ & $\begin{array}{c}0.037 \pm 0.002 \\
(p<0.0001)\end{array}$ & $\begin{array}{c}0.035 \pm 0.002 \\
(p<0.0001)\end{array}$ & $\begin{array}{c}0.032 \pm 0.001 \\
(p<0.0001)\end{array}$ \\
\hline$p$ & $\begin{array}{c}0.098 \pm 0.001 \\
(p<0.0001)\end{array}$ & $\begin{array}{c}0.098 \pm 0.002 \\
(p<0.0001)\end{array}$ & $\begin{array}{c}0.098 \pm 0.001 \\
(p<0.0001)\end{array}$ & $\begin{array}{c}0.098 \pm 0.002 \\
(p<0.0001)\end{array}$ & $\begin{array}{c}0.098 \pm 0.001 \\
(p<0.0001)\end{array}$ & $\begin{array}{c}0.098 \pm 0.002 \\
(p<0.0001)\end{array}$ \\
\hline$q$ & $\begin{array}{c}0.073 \pm 0.003 \\
(p<0.0001)\end{array}$ & $\begin{array}{c}0.073 \pm 0.001 \\
(p<0.0001)\end{array}$ & $\begin{array}{c}0.073 \pm 0.004 \\
(p<0.0001)\end{array}$ & $\begin{array}{c}0.073 \pm 0.003 \\
(p<0.0001)\end{array}$ & $\begin{array}{c}0.037 \pm 0.006 \\
(p<0.0001)\end{array}$ & $\begin{array}{c}0.107 \pm 0.001 \\
(p<0.0001)\end{array}$ \\
\hline$r$ & $\begin{array}{c}-0.103 \pm 0.011 \\
(p<0.0001)\end{array}$ & $\begin{array}{c}-0.103 \pm 0.009 \\
(p<0.0001)\end{array}$ & $\begin{array}{c}-0.103 \pm 0.015 \\
(p<0.0001)\end{array}$ & $\begin{array}{c}-0.103 \pm 0.021 \\
(p<0.0001)\end{array}$ & $\begin{array}{c}-0.103 \pm 0.008 \\
(p<0.0001)\end{array}$ & $\begin{array}{c}-0.103 \pm 0.013 \\
(p<0.0001)\end{array}$ \\
\hline$R_{B T^{2}}$ & 0.9975 & 0.9974 & 0.9985 & 0.9934 & 0.9971 & 0.9988 \\
\hline$R P D M$ & 18.0670 & 17.3313 & 16.4117 & 20.0055 & 17.1747 & 15.0306 \\
\hline$B_{f}$ & 1.1513 & 1.1488 & 1.1279 & 1.1670 & 1.1209 & 1.1187 \\
\hline$A_{f}$ & 1.1542 & 1.1493 & 1.1388 & 1.1758 & 1.1459 & 1.1286 \\
\hline$F$-ratio & 7764.25 & 9873.12 & 8895.19 & 7983.49 & 10895.37 & 3211.61 \\
\hline$p$-value & $<0.0001$ & $<0.0001$ & $<0.0001$ & $<0.0001$ & $<0.0001$ & $<0.0001$ \\
\hline
\end{tabular}

The parameter value is considered statistically significant if its corresponding $p$-value is lower than 0.05 . 

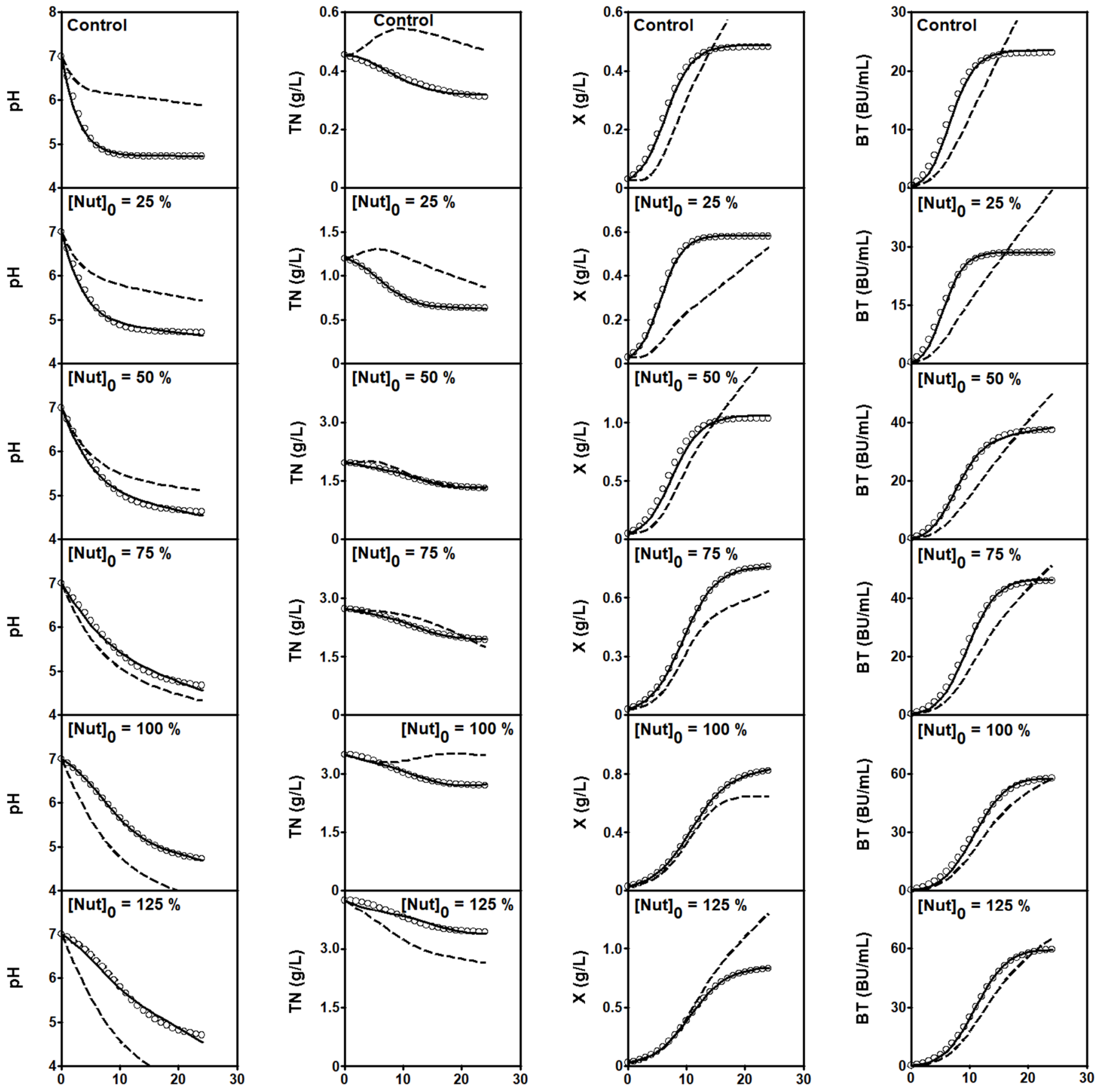

Time (h)

Figure 4. Experimental data (symbols) of culture $\mathrm{pH}$, TN consumption, and $\mathrm{X}$ and Nis formation by L. lactis CECT 539 in batch cultures in DW medium supplemented with 0, 25, 50, 75, 100, and $125 \%(w / v)$ of the standard concentrations of the MRS broth nutrients ([Nut $]_{0}$ ) with the exception of glucose and Tween 80. Dashed lines drawn through the experimental data are predictions of the global four-dimensional predator-prey system (1)-(4) obtained with the parameters shown in Table 3. Solid lines were obtained by adjusting the four-dimensional predator-prey system (1)-(4) to the experimental data corresponding to each individual culture (see parameter values in Table 7). 
Table 7. Statistically significant $(p<0.05)$ parameter values (as estimates \pm confidence intervals) calculated with the four-dimensional predator-prey system (1)-(4) for each individual culture of the series of fermentation DW-MRS.

\begin{tabular}{|c|c|c|c|c|c|c|}
\hline \multirow[b]{2}{*}{ Parameter } & \multicolumn{6}{|c|}{ Initial Nutrient Concentrations $(\%, w / v)$ in the DW Medium } \\
\hline & 0 & 25 & 50 & 75 & 100 & 125 \\
\hline$a$ & $\begin{array}{c}-0.032 \pm 0.001 \\
(p<0.0001)\end{array}$ & $\begin{array}{c}-0.037 \pm 0.001 \\
(p<0.0001)\end{array}$ & $\begin{array}{c}-0.043 \pm 0.002 \\
(p<0.0001)\end{array}$ & $\begin{array}{c}0.177 \pm 0.002 \\
(p<0.0001)\end{array}$ & $\begin{array}{c}0.290 \pm 0.015 \\
(p<0.0001)\end{array}$ & $\begin{array}{c}0.282 \pm 0.004 \\
(p<0.0001)\end{array}$ \\
\hline$b$ & $\begin{array}{c}-0.017 \pm 0.001 \\
(p<0.0001)\end{array}$ & $\begin{array}{c}-0.016 \pm 0.003 \\
(p<0.0001)\end{array}$ & $\begin{array}{c}-0.014 \pm 0.001 \\
(p<0.0001)\end{array}$ & $\begin{array}{c}0.022 \pm 0.000 \\
(p<0.0001)\end{array}$ & $\begin{array}{c}0.039 \pm 0.002 \\
(p<0.0001)\end{array}$ & $\begin{array}{c}0.038 \pm 0.001 \\
(p<0.0001)\end{array}$ \\
\hline$c$ & $\begin{array}{c}0.103 \pm 0.002 \\
(p<0.0001)\end{array}$ & $\begin{array}{c}0.057 \pm 0.001 \\
(p<0.0001)\end{array}$ & $\begin{array}{c}0.022 \pm 0.001 \\
(p<0.0001)\end{array}$ & $\begin{array}{c}0.086 \pm 0.001 \\
(p<0.0001)\end{array}$ & $\begin{array}{c}0.116 \pm 0.010 \\
(p<0.0001)\end{array}$ & $\begin{array}{c}0.115 \pm 0.008 \\
(p<0.0001)\end{array}$ \\
\hline$R_{p H^{2}}$ & 0.9964 & 0.9950 & 0.9941 & 0.9987 & 0.9994 & 0.9991 \\
\hline$R P D M$ & 0.5787 & 0.8501 & 1.0040 & 0.4249 & 0.3100 & 0.3525 \\
\hline$B_{f}$ & 0.9997 & 0.9989 & 0.9988 & 1.0001 & 1.0001 & 1.0003 \\
\hline$A_{f}$ & 1.0058 & 1.0086 & 1.0101 & 1.0043 & 1.0031 & 1.0035 \\
\hline$F$-ratio & 378.83 & 375.38 & 371.42 & 396.38 & 422.44 & 409.56 \\
\hline$p$-value & $<0.0001$ & $<0.0001$ & $<0.0001$ & $<0.0001$ & $<0.0001$ & $<0.0001$ \\
\hline$d$ & $\begin{array}{c}-0.068 \pm 0.001 \\
(p<0.0001)\end{array}$ & $\begin{array}{c}-0.189 \pm 0.002 \\
(p<0.0001)\end{array}$ & $\begin{array}{c}-0.355 \pm 0.015 \\
(p<0.0001)\end{array}$ & $\begin{array}{c}-0.379 \pm 0.016 \\
(p<0.0001)\end{array}$ & $\begin{array}{c}0.364 \pm 0.005 \\
(p<0.0001)\end{array}$ & $\begin{array}{c}0.416 \pm 0.002 \\
(p<0.0001)\end{array}$ \\
\hline$e$ & $\begin{array}{c}-0.415 \pm 0.004 \\
(p<0.0001)\end{array}$ & $\begin{array}{c}-0.430 \pm 0.006 \\
(p<0.0001)\end{array}$ & $\begin{array}{c}-0.382 \pm 0.003 \\
(p<0.0001)\end{array}$ & $\begin{array}{c}-0.297 \pm 0.011 \\
(p<0.0001)\end{array}$ & $\begin{array}{c}0.066 \pm 0.001 \\
(p<0.0001)\end{array}$ & $\begin{array}{c}0.068 \pm 0.003 \\
(p<0.0001)\end{array}$ \\
\hline$f$ & $\begin{array}{c}0.292 \pm 0.011 \\
(p<0.0001)\end{array}$ & $\begin{array}{c}0.338 \pm 0.007 \\
(p<0.0001)\end{array}$ & $\begin{array}{c}0.392 \pm 0.004 \\
(p<0.0001)\end{array}$ & $\begin{array}{c}0.395 \pm 0.020 \\
(p<0.0001)\end{array}$ & $\begin{array}{c}0.230 \pm 0.016 \\
(p<0.0001)\end{array}$ & $\begin{array}{c}0.148 \pm 0.011 \\
(p<0.0001)\end{array}$ \\
\hline$g$ & $\begin{array}{c}-0.007 \pm 0.001 \\
(p<0.0001)\end{array}$ & $\begin{array}{c}-0.012 \pm 0.002 \\
(p<0.0001)\end{array}$ & $\begin{array}{c}-0.010 \pm 0.001 \\
(p<0.0001)\end{array}$ & $\begin{array}{c}-0.008 \pm 0.000 \\
(p<0.0001)\end{array}$ & $\begin{array}{c}-0.001 \pm 0.000 \\
(p<0.0001)\end{array}$ & $\begin{array}{c}-0.001 \pm 0.000 \\
(p<0.0001)\end{array}$ \\
\hline$h$ & $\begin{array}{c}0.016 \pm 0.001 \\
(p<0.0001)\end{array}$ & $\begin{array}{c}0.045 \pm 0.001 \\
(p<0.0001)\end{array}$ & $\begin{array}{c}0.057 \pm 0.001 \\
(p<0.0001)\end{array}$ & $\begin{array}{c}0.061 \pm 0.002 \\
(p<0.0001)\end{array}$ & $\begin{array}{c}0.018 \pm 0.001 \\
(p<0.0001)\end{array}$ & $\begin{array}{c}0.018 \pm 0.001 \\
(p<0.0001)\end{array}$ \\
\hline$R_{T N}^{2}$ & 0.9871 & 0.9982 & 0.9978 & 0.9850 & 0.9992 & 0.9962 \\
\hline$R P D M$ & 1.2891 & 0.9744 & 0.5372 & 1.7542 & 0.2335 & 0.2001 \\
\hline$B_{f}$ & 1.0013 & 1.0004 & 0.9996 & 0.9975 & 0.9998 & 0.9997 \\
\hline$A_{f}$ & 1.0129 & 1.0098 & 1.0054 & 1.0178 & 1.0023 & 1.0020 \\
\hline$F$-ratio & 1212.37 & 1311.19 & 1309.21 & 1125.41 & 1321.28 & 1285.43 \\
\hline$p$-value & $<0.0001$ & $<0.0001$ & $<0.0001$ & $<0.0001$ & $<0.0001$ & $<0.0001$ \\
\hline$i$ & $\begin{array}{c}0.928 \pm 0.013 \\
(p<0.0001)\end{array}$ & $\begin{array}{c}1.103 \pm 0.016 \\
(p<0.0001)\end{array}$ & $\begin{array}{c}1.106 \pm 0.008 \\
(p<0.0001)\end{array}$ & $\begin{array}{c}1.110 \pm 0.014 \\
(p<0.0001)\end{array}$ & $\begin{array}{c}1.118 \pm 0.024 \\
(p<0.0001)\end{array}$ & $\begin{array}{c}1.243 \pm 0.011 \\
(p<0.0001)\end{array}$ \\
\hline$j$ & $\begin{array}{c}0.731 \pm 0.010 \\
(p<0.0001)\end{array}$ & $\begin{array}{c}0.830 \pm 0.019 \\
(p<0.0001)\end{array}$ & $\begin{array}{c}0.542 \pm 0.025 \\
(p<0.0001)\end{array}$ & $\begin{array}{c}0.289 \pm 0.005 \\
(p<0.0001)\end{array}$ & $\begin{array}{c}0.139 \pm 0.003 \\
(p<0.0001)\end{array}$ & $\begin{array}{c}0.021 \pm 0.002 \\
(p<0.0001)\end{array}$ \\
\hline$k$ & $\begin{array}{c}0.007 \pm 0.001 \\
(p<0.0001)\end{array}$ & $\begin{array}{c}0.007 \pm 0.001 \\
(p<0.0001)\end{array}$ & $\begin{array}{c}0.007 \pm 0.001 \\
(p<0.0001)\end{array}$ & $\begin{array}{c}0.007 \pm 0.000 \\
(p<0.0001)\end{array}$ & $\begin{array}{c}0.007 \pm 0.000 \\
(p<0.0001)\end{array}$ & $\begin{array}{c}0.007 \pm 0.001 \\
(p<0.0001)\end{array}$ \\
\hline$l$ & $\begin{array}{c}0.087 \pm 0.004 \\
(p<0.0001)\end{array}$ & $\begin{array}{c}0.087 \pm 0.003 \\
(p<0.0001)\end{array}$ & $\begin{array}{c}0.087 \pm 0.004 \\
(p<0.0001)\end{array}$ & $\begin{array}{c}0.086 \pm 0.002 \\
(p<0.0001)\end{array}$ & $\begin{array}{c}0.086 \pm 0.001 \\
(p<0.0001)\end{array}$ & $\begin{array}{c}0.091 \pm 0.001 \\
(p<0.0001)\end{array}$ \\
\hline$m$ & $\begin{array}{c}0.019 \pm 0.002 \\
(p<0.0001)\end{array}$ & $\begin{array}{c}0.019 \pm 0.001 \\
(p<0.0001)\end{array}$ & $\begin{array}{c}0.080 \pm 0.002 \\
(p<0.0001)\end{array}$ & $\begin{array}{c}0.080 \pm 0.004 \\
(p<0.0001)\end{array}$ & $\begin{array}{c}0.076 \pm 0.003 \\
(p<0.0001)\end{array}$ & $\begin{array}{c}0.090 \pm 0.002 \\
(p<0.0001)\end{array}$ \\
\hline$R_{X}^{2}$ & 0.9994 & 0.9999 & 0.9994 & 0.9987 & 0.9998 & 0.9991 \\
\hline$R P D M$ & 2.6384 & 0.7688 & 2.6386 & 2.0128 & 1.8566 & 4.4775 \\
\hline$B_{f}$ & 0.9785 & 0.9946 & 0.9787 & 0.9964 & 0.9862 & 0.9671 \\
\hline$A_{f}$ & 1.0279 & 1.0078 & 1.0277 & 1.0204 & 1.0191 & 1.0480 \\
\hline$F$-ratio & 6014.11 & 7051.64 & 6001.32 & 4318.51 & 6886.49 & 4806.29 \\
\hline$p$-value & $<0.0001$ & $<0.0001$ & $<0.0001$ & $<0.0001$ & $<0.0001$ & $<0.0001$ \\
\hline$n$ & $\begin{array}{c}0.546 \pm 0.024 \\
(p<0.0001)\end{array}$ & $\begin{array}{c}0.899 \pm 0.013 \\
(p<0.0001)\end{array}$ & $\begin{array}{c}0.967 \pm 0.019 \\
(p<0.0001)\end{array}$ & $\begin{array}{c}1.134 \pm 0.010 \\
(p<0.0001)\end{array}$ & $\begin{array}{c}1.186 \pm 0.008 \\
(p<0.0001)\end{array}$ & $\begin{array}{c}1.225 \pm 0.015 \\
(p<0.0001)\end{array}$ \\
\hline$o$ & $\begin{array}{c}0.015 \pm 0.001 \\
(p<0.0001)\end{array}$ & $\begin{array}{c}0.015 \pm 0.001 \\
(p<0.0001)\end{array}$ & $\begin{array}{c}0.009 \pm 0.001 \\
(p<0.0001)\end{array}$ & $\begin{array}{c}0.007 \pm 0.001 \\
(p<0.0001)\end{array}$ & $\begin{array}{c}0.005 \pm 0.001 \\
(p<0.0001)\end{array}$ & $\begin{array}{c}0.004 \pm 0.001 \\
(p<0.0001)\end{array}$ \\
\hline$p$ & $\begin{array}{c}0.385 \pm 0.010 \\
(p<0.0001)\end{array}$ & $\begin{array}{c}0.385 \pm 0.007 \\
(p<0.0001)\end{array}$ & $\begin{array}{c}0.385 \pm 0.013 \\
(p<0.0001)\end{array}$ & $\begin{array}{c}0.385 \pm 0.014 \\
(p<0.0001)\end{array}$ & $\begin{array}{c}0.385 \pm 0.004 \\
(p<0.0001)\end{array}$ & $\begin{array}{c}0.385 \pm 0.018 \\
(p<0.0001)\end{array}$ \\
\hline$q$ & $\begin{array}{c}0.003 \pm 0.000 \\
(p<0.0001)\end{array}$ & $\begin{array}{c}0.049 \pm 0.003 \\
(p<0.0001)\end{array}$ & $\begin{array}{c}0.077 \pm 0.002 \\
(p<0.0001)\end{array}$ & $\begin{array}{c}0.106 \pm 0.008 \\
(p<0.0001)\end{array}$ & $\begin{array}{c}0.120 \pm 0.004 \\
(p<0.0001)\end{array}$ & $\begin{array}{c}0.127 \pm 0.0015 \\
(p<0.0001)\end{array}$ \\
\hline$r$ & $\begin{array}{c}0.013 \pm 0.002 \\
(p<0.0001)\end{array}$ & $\begin{array}{c}0.013 \pm 0.003 \\
(p<0.0001)\end{array}$ & $\begin{array}{c}0.013 \pm 0.001 \\
(p<0.0001)\end{array}$ & $\begin{array}{c}0.013 \pm 0.001 \\
(p<0.0001)\end{array}$ & $\begin{array}{c}0.013 \pm 0.001 \\
(p<0.0001)\end{array}$ & $\begin{array}{c}0.013 \pm 0.003 \\
(p<0.0001)\end{array}$ \\
\hline$R_{B T^{2}}$ & 0.9991 & 0.9984 & 0.9994 & 0.9994 & 0.9986 & 0.9987 \\
\hline$R P D M$ & 4.8680 & 5.8719 & 6.4048 & 7.4056 & 11.5425 & 11.6937 \\
\hline$B_{f}$ & 0.9541 & 0.9405 & 0.9330 & 0.9237 & 0.8769 & 0.8765 \\
\hline$A_{f}$ & 1.0556 & 1.0719 & 1.0781 & 1.0890 & 1.1505 & 1.1503 \\
\hline$F$-ratio & 892.54 & 808.19 & 801.22 & 2315.09 & 1366.93 & 2404.16 \\
\hline$p$-value & $<0.0001$ & $<0.0001$ & $<0.0001$ & $<0.0001$ & $<0.0001$ & $<0.0001$ \\
\hline
\end{tabular}

The parameter value is considered statistically significant if its corresponding $p$-value is lower than 0.05 . 
When the global Equations (1)-(4) were set to describe the time course of the culture pH, TN, X, and BT in the DW-G, DW-TS-TP, and DW-MRS series of cultures, the results obtained were not satisfactory. Thus, although in some cases, statistically significant values $(p<0.0001)$ for both the parameters and global $\mathrm{pH}$ equations were obtained, the values of $\mathrm{R}_{\mathrm{pH}}{ }^{2}$ and F-ratio were relatively low, the RPDM values were almost always higher than 10, and both the $B_{f}$ and $A_{f}$ values were generally far from one (Table 3 ). In addition, the $p H$, TN, X, and BT trajectories predicted by the global Equations (1)-(4) for the three series of cultures showed a clear deviation from the experimental $\mathrm{pH}, \mathrm{TN}, \mathrm{X}$, and BT data (dashed lines in Figures 1-4).

These observations suggest that the four-dimensional predator-prey system could not be used as a general equation to describe the nisin production system in the DW-G, DW-TS-TP, and DW-MRS series of batch fermentations.

These unsatisfactory results could be related to the different initial compositions of the media used in each series of cultures: DW media supplemented with different initial concentrations of glucose (Figure 1), TS and TP (Figures 2 and 3), and MRS broth nutrients (Figure 4). Therefore, it could be considered that, in each series of cultures, each fermentation was independent of the other ones since the fermentation substrates used were different. So that the different initial media composition in the following three series of batch fermentations (DW-G, DW-TS-TP, and DW-MRS) modulated the time-course of the culture variables: $\mathrm{pH}$ and the concentrations of total nitrogen, biomass, and nisin (Figures 1-4). In this way, it is well known that the initial culture conditions affect the evolution of these culture variables $(\mathrm{pH}, \mathrm{TN}, \mathrm{X}$, and BT) in different ways [8,16-18,21]. For example, the $\mathrm{pH}$ drop depends on the presence and interaction between some compounds (salts, organic acids, proteins, and free amino acids) with buffering capacity in the culture medium [22] and organic acid production by growing cells [16-18]. TN consumption during fermentation depends on the initial medium composition, mainly the type and concentration of the nitrogen source [5,16-18,21] and culture $\mathrm{pH}[18,20]$. In fact, the consumption of TN [18] or amino acids [20] in L. lactis strains was maximal when the culture $\mathrm{pH}$ reached values between 5.8 and 6.5 , and decreased abruptly for high and low $\mathrm{pH}$ values.

On the other hand, biomass production depends on different factors, including the initial medium composition (concentration and type of nutrients, mainly carbon, nitrogen, and phosphorous sources), initial and final $\mathrm{pH}$ values in the cultures, $\mathrm{pH}$ evolution, and production of inhibitory compounds [5,16-18]. Nisin synthesis depends not only on the time course of biomass concentration, but also on (i) the amount of biomass produced, (ii) the initial concentration and type of nutrient (carbon, nitrogen, and phosphorous sources), and (iii) initial and final $\mathrm{pH}$ value, $\mathrm{pH}$ evolution, and $\mathrm{pH}$ drop generated in the cultures $[5,8,12,16-18]$. So that the specific effects of these factors on the response variables (culture $\mathrm{pH}, \mathrm{TN}$ consumption, biomass, and nisin production) could be non-synchronous, producing a different change in the time course of the latter variables and, consequently, in their relationships.

For example, the buffering capacity $(\mathrm{BC})$, which is a measure of the resistance of the culture medium to $\mathrm{pH}$ changes, affects biomass and nisin synthesis differently. On the one hand, the increase in BC favors biomass production since the cultures remain longer within the optimum $\mathrm{pH}$ range (between 5.8 and 6.5) for nutrient consumption for L. lactis CECT $539[18,20]$. On the other hand, these high $\mathrm{pH}$ values inhibit bacteriocin synthesis, which was higher at an optimum pH value of 4.90 in DW medium. The latter was due to the need for a low $\mathrm{pH}$ value to favor the maturation of the nisin molecule $[5,18]$. The value of this optimum final $\mathrm{pH}$ for nisin production depends on the producer strain and composition of the culture medium $[8,12,23]$.

In addition, it has been observed that higher $\mathrm{pH}$ drops $(\mathrm{rpH})$ enhance nisin production $[12,18]$ before the cultures reached an inappropriate $\mathrm{pH}$ for survival and cell growth of L. lactis [24]. Thus, in the series of fermentations DW-G, DW-TS-TP, and DW-MRS 
(Figures 1-4), it can be observed that the evolution of culture $\mathrm{pH}$, biomass production, and nisin synthesis in each culture was different.

For these reasons, it is very difficult to develop a general four-dimensional predatorprey system to explain the variations in the time courses of the four variables (culture $\mathrm{pH}$, $\mathrm{TN}, \mathrm{X}$, and BT) for each or all series of cultures. In addition, with the use of a general four-dimensional equation, the effect of different initial culture conditions on the evolution of the four dependent variables could not be explained, leading to a misinterpretation of the kinetics of the cultures.

To solve this problem, we first fitted the four-dimensional predator-prey system (1)-(4) to each individual culture of each series of fermentation to accurately determine how the values of the different parameters change with changes in the initial culture conditions (concentrations of glucose, TP and TS, and MRS broth nutrients). Afterward, we intend to modify the four-dimensional predator-prey system (1)-(4) (when this was possible) by including a term for the specific effect of the initial culture conditions on the evolution of $\mathrm{pH}, \mathrm{TN}, \mathrm{X}$, and BT.

\subsection{Modeling the Batch Nisin Production System in Individual Cultures Corresponding to Each} Series of Fermentations

When the four-dimensional predator-prey system (1)-(4) was used to describe the relationships between the four response variables $(\mathrm{pH}, \mathrm{TN}, \mathrm{X}$, and $\mathrm{BT})$ in each individual culture, both equations and the values of the parameters were statistically significant $(p<0.050)$, with $R^{2}$ and $F$-values considerably higher, and $B_{f}$ and $A_{f}$ values $\sim 1$ (Tables 4-7).

In addition, the predictions of the four-dimensional predator-prey system (1)-(4) for each response variable (solid lines in Figures 1-4) were in perfect agreement with the corresponding experimental data. This indicates that the developed four-dimensional predator-prey system (1)-(4) is consistent and robust enough to accurately describe the trend observed in the experimental data of culture $\mathrm{pH}, \mathrm{TN}, \mathrm{X}$, and BT.

The results obtained for each series of fermentations are discussed below.

\subsubsection{Series of Fermentation DW-G}

Table 4 shows the parameter values as well as the statistical analysis obtained when the four-dimensional predator-prey system (1)-(4) was fitted to the experimental data of cultures $\mathrm{pH}, \mathrm{TN}, \mathrm{X}$, and $\mathrm{BT}$ in the DW-G cultures.

In this case, all values of the parameters in Equations (1)-(4) were significant $(p<0.05)$ and considerably higher values for $R_{p H}{ }^{2}$ (between 0.9968 and 0.9980), $R_{T N}{ }^{2}$ (between 0.9987 and 0.9998), $R_{X}{ }^{2}$ (between 0.9990 and 1.0000), and $R_{B T}{ }^{2}$ (between 0.9992 and 1.0000) were obtained. In addition, the values of $B_{f}$ and $A_{f}$ calculated for Equations (1)-(4) were $\sim 1$ and the RPDM values were considerably lower than $10 \%$ (Table 4). Therefore, it could be considered that the use of the four-dimensional predator-prey system (1)-(4) accurately described the trend observed for the culture $\mathrm{pH}, \mathrm{TN}, \mathrm{X}$, and BT in the DW-G cultures.

Regarding the equation parameters, it can be noted that the values of $a$ and $b$ in Equation (1) had a negative sign and their absolute values decreased (Table 4). This is because the culture $\mathrm{pH}$ drop (the difference between the initial and final $\mathrm{pH}$ values) decreased and the final $\mathrm{pH}$ increased with the increase in the initial concentration of glucose $\left[G_{0}\right]$ (from 0 to $25 \mathrm{~g} / \mathrm{L}$ ) in the media (Figure 1). In addition, the value of $c$ decreased from 0.039 to 0.002 with the increase in $\left[G_{0}\right]$ due to the inhibition that increasing glucose concentration produced on the growth of L. lactis CECT 539 and, consequently, on lactic acid production [16], causing a gradual reduction in the $\mathrm{pH}$ drop in the culture media (Figure 1).

In the case of Equation (2), negative values for $d, e, f$, and $g$, and positive values for $h$ were obtained (Table 4). The decrease in the absolute values obtained for $d$ and $e$ could be related to the reduction in the TN consumption rates and the increase in the final TN values observed with the increase in $\left[G_{0}\right]$ (Figure 1). Similarly, the values of $f, g$, and $h$ were almost 
similar for all cultures because the TN consumption decreased with the increase in $\left[G_{0}\right]$, in parallel with the reduction in biomass production, nisin synthesis, and $\mathrm{pH}$ drop (Figure 1).

Equation (3) also provides an accurate description of biomass production in each culture. In this case, the values of $i$ decreased because of the inhibition that the increasing initial glucose concentrations produced on the growth rate of L. lactis (Figure 1). On the other hand, the value of $j$ did not vary, indicating that the reduction in the growth rate was proportional to the reduction in the maximum biomass concentration produced in the different cultures (Figure 1).

Similarly, a constant value for $k$ was obtained, indicating that the competition between biomass production and nisin synthesis for the nitrogen source was very similar in the different glucose-supplemented cultures. As observed in Figure 1, the reduction in growth caused by the increase in $\left[G_{0}\right]$ was proportional to that observed in nisin synthesis because this bacteriocin was produced in this series of cultures as a $\mathrm{pH}$-dependent primary metabolite [16].

As expected, the values of $l$ and $m$ decreased (Table 4 ), due to the decrease in the $\mathrm{pH}$ drops and TN consumption caused by the reduction in biomass production (Figure 1).

The detailed analysis of the results obtained for Equation (4) showed a decrease in the values of $n$ in agreement with the reduction in nisin production with the increase in $\left[G_{0}\right]$ (Figure 1). The constant value obtained for the $o$ constant could be explained by a proportional decrease in the nisin production rate and maximum nisin levels produced by L. lactis CECT 539. The constant value obtained for $p$ is in perfect agreement with the constant value obtained for $k$ in Equation (3), indicating again that the competition between biomass production and nisin synthesis for the nitrogen source was very similar in the different glucose-supplemented cultures.

The decrease in the values obtained for $q$ could be explained by the fact that the reduction in $\mathrm{pH}$ drops with the increase in $\left[G_{0}\right]$ negatively affected the synthesis of nisin. In the unsupplemented culture $\left(\left[G_{0}\right]=0\right)$, the final $\mathrm{pH}$ value was 4.73 , which is in perfect agreement with the optimum final $\mathrm{pH}$ between 4.78 and 4.90 observed in L. lactis cultures in whey [8]. In contrast, a constant value was obtained for $r$ (Table 4), indicating proportional TN consumption for nisin synthesis.

These results corroborate the affirmation that nisin was produced by L. lactis CECT 539 as a pH-dependent primary metabolite [16] and indicate that the TN consumption was proportional to the production of bacteriocin and biomass.

As discussed above, each culture variable ( $\mathrm{pH}, \mathrm{TN}, \mathrm{X}$, and $\mathrm{BT})$ evolved, describing a similar profile in the different fermentations of the DW-G series (Figure 1). However, the rates of culture $\mathrm{pH}(r p H(t))$ and $\mathrm{TN}(r T N(t))$ decreased, and biomass $(r X(t))$ and nisin $(r B T(t))$ production in the glucose-supplemented cultures did not exhibit a clear trend compared with the respective rates in the culture in the unsupplemented culture (Figure 5).

From the detailed observation of Figure 5, it can be noted that the highest $r p H(t), r \mathrm{X}(t)$, $r B T(t))$, and $r T N(t)$ were obtained in the unsupplemented DW substrate during the first 4 , 8,9 , and $12 \mathrm{~h}$ of fermentation, respectively. However, after these times, the four rates in the unsupplemented DW medium were lower than the corresponding rates calculated in the glucose-supplemented cultures.

For this reason, the four-dimensional Equations (1)-(4) could not be modified by including a term for explaining the inhibitory effect of the increase in $\left[G_{0}\right]$ on the rates $r p H(t), r T N(t), r X(t)$, and $r B T(t))$. 

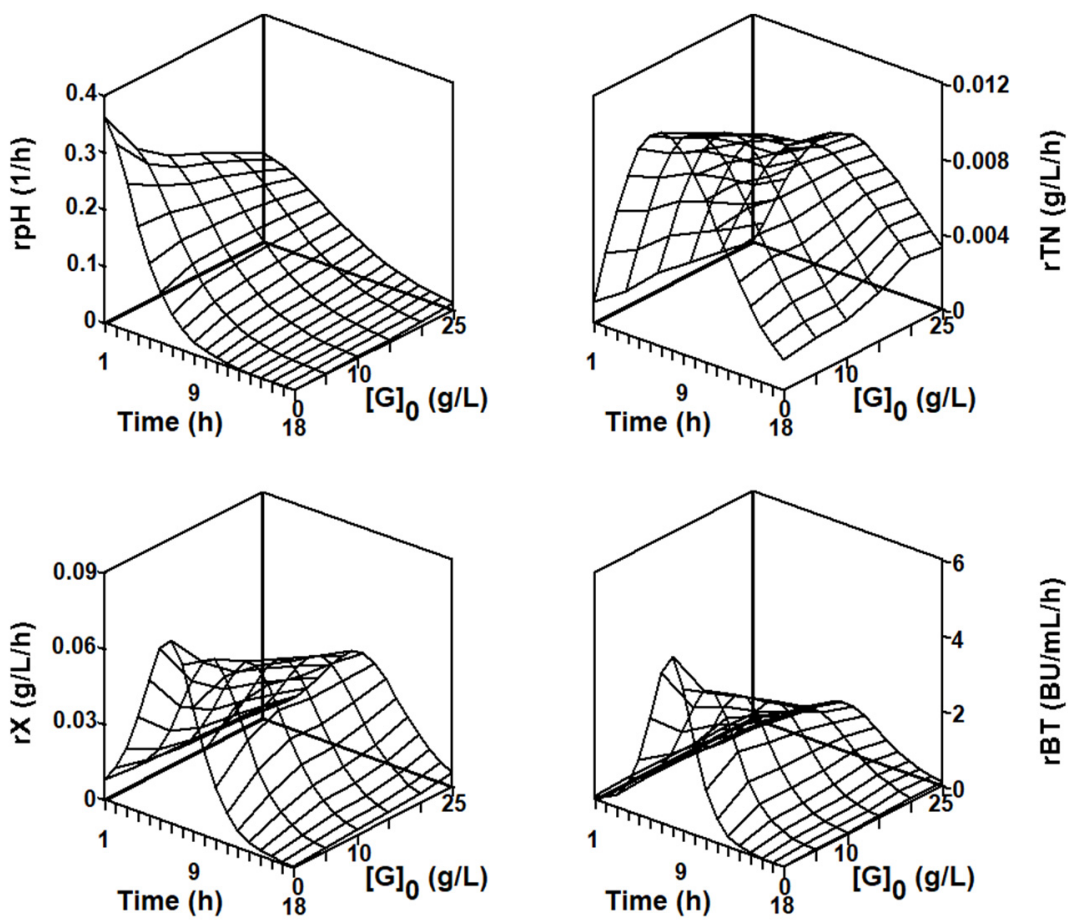

Figure 5. Response surfaces showing the time courses of the experimental rates of $\mathrm{pH}, \mathrm{TN}, \mathrm{X}$, and Nis, as a function of the initial glucose concentration ( $[G]_{0}=0,5,10,15,20$, and $\left.25 \mathrm{~g} / \mathrm{L}\right)$ in the DW medium. The different rates were obtained from the experimental data shown in Figure 1.

\subsubsection{Series of Fermentation DW-TS-TP}

Tables 5 and 6 show the results obtained when the four-dimensional Equations (1)-(4) was fitted to each individual culture of the series of fermentation DW-TS-TP. The predictions of Equations (1)-(4) are shown as solid lines in Figures 2 and 3. As observed before for the series of fermentation DW-G, the DW-TS-TP cultures were satisfactorily described using this modeling procedure (Tables 5 and 6).

The values of $a, b$, and $c$ in Equation (1), as expected, depended on the initial chemical composition of the media (mainly the initial concentrations of TS and TP). So that the highest $a$ value was obtained in the culture performed at the optimum conditions (TS $=22.6 \mathrm{~g} / \mathrm{L}, \mathrm{TP}=0.46 \mathrm{~g} / \mathrm{L}$, Table 6), in which the highest $\mathrm{pH}$ drop (difference between the initial and final $\mathrm{pH}$ value) was generated (Figures 2 and 3). The calculated values for $b$ and $c$ varied between 0.007 and 0.013 and between 0.033 and 0.057 , respectively (Tables 5 and 6), which were dependent on the growth of L. lactis in the different cultures (Figures 2 and 3).

The highest values for $d$ and $f$ in Equation (2) were obtained at the optimum conditions (Table 6), in which the highest amounts of TN and biomass were consumed $(0.230 \mathrm{~g} / \mathrm{L})$ and produced $(0.716 \mathrm{~g} / \mathrm{L})$, respectively (Figures 2 and 3$)$. This suggests that the total nitrogen source consumption depended on the initial composition of the fermentation medium, as indicated before $[2,5,16-18]$. The value of $e$ depended on the initial media composition, but the values of $g$ and $h$ were constant, indicating a proportional consumption of TN for nisin production and a similar effect of $\mathrm{pH}$ on $\mathrm{TN}$ assimilation.

The maximum growth rate was observed in the culture performed at TS $=22.60 \mathrm{~g} / \mathrm{L}$, $\mathrm{TP}=0.46 \mathrm{~g} / \mathrm{L}$, and in accordance with this, the highest value for $i$ in Equation (3) was obtained (Tables 5 and 6). In addition, the values of $j$ and $l$ varied as a function of the initial TS and TP concentrations in the different culture media, but the value of the competition coefficient $k$ was constant in the different cultures, indicating a proportional efficiency of TN utilization for biomass production and nisin synthesis. The constant value calculated for $m$ suggests that the nitrogen source consumption was directly correlated with biomass production. 
When Equation (4) was fitted to the experimental data of nisin synthesis, the highest $n$ value was obtained in the culture performed at the optimum conditions (Tables 5 and 6) due to the highest bacteriocin production rate observed in this culture (Figures 2 and 3). The coefficient $o$ did not show a significant variation since the relationship between the nisin synthesis rates and the maximum bacteriocin levels produced in the cultures was almost constant. Additionally, the coefficients $p, q$, and $r$ exhibited constant values, suggesting constancy in the competition between biomass and nisin production for the TN source and in the effect of $\mathrm{pH}$ and $\mathrm{TN}$ consumption on bacteriocin synthesis.

However, in the case of nisin production, the values of RPDM corresponding to some cultures were higher than $10 \%$ (Tables 5 and 6), due to the lack of fit between the experimental and calculated values observed during the first $7 \mathrm{~h}$ of fermentation (Figures 2 and 3). This was probably because nisin production was quantified by a photometric bioassay using an indicator strain [16] and, consequently, the experimental error in determining nisin titers could be greater than that of the analytical methods used in $\mathrm{pH}$, total nitrogen, and biomass measurements. So that in nisin determination, the differences between the experimental and predicted values during the first $7 \mathrm{~h}$ of fermentation were low (Figures 2 and 3), but the experimental nisin data in this interval, used as the denominator in Equation (8), were also considerably low, increasing the RPDM value (Tables 5 and 6).

In the series of cultures DW-TS-TP, the effects of the initial TS and TP concentrations on both the growth and bacteriocin production were described by empirical quadratic equations [17]. The inclusion of terms for explaining these effects in the four-dimensional predator-prey system (1)-(4) could contribute to obtaining a general equation for describing the evolution of the four response variables $(\mathrm{pH}, \mathrm{TN}, \mathrm{X}$, and BT). However, this approach has several drawbacks since too large equations could be obtained, and information about the true relationship between the dependent variables $(p H(t), T N(t), X(t), B T(t))$, and the own essence of the LV equation would be lost.

In fact, the rates of culture $\mathrm{pH}$ drop $(r p H)$, total nitrogen consumption $(r T N)$, and biomass $(r X)$ and nisin $(r B T)$ production in the different experiments (1-14) did not show a clear dependence on changes in initial TS and TP concentrations (Figure 6).
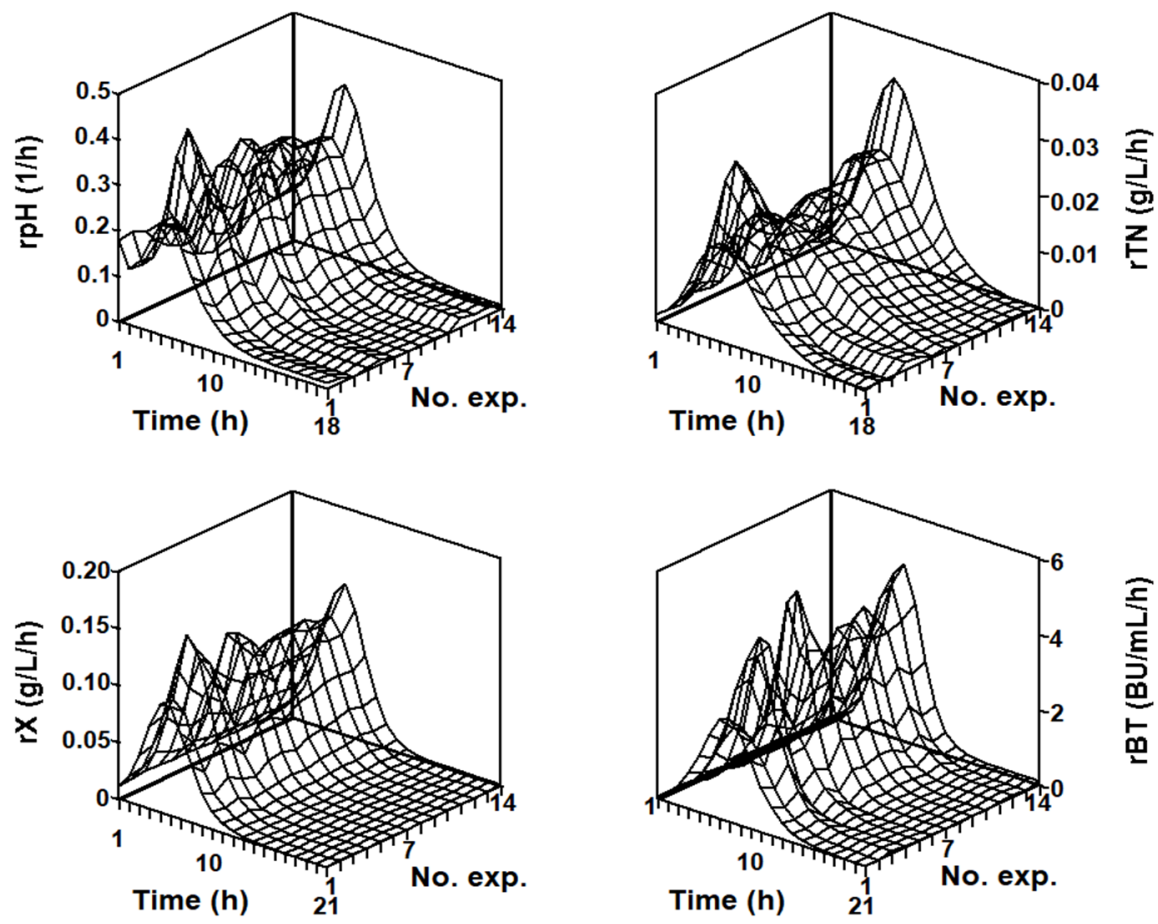

Figure 6. Response surfaces showing the time courses of the experimental rates of $\mathrm{pH}, \mathrm{TN}, \mathrm{X}$, and Nis in the 14 experiments (No. exp. $=1-14$ ) performed at different initial TS and TP concentrations. The different rates were obtained from the experimental data shown in Figures 2 and 3. 


\subsubsection{Series of Fermentation DW-MRS}

In this series of fermentation, the absolute values of the constant $a$ increased when the DW medium was supplemented with MRS nutrients from 0 to $50 \%$ (fermentations DW-MR0\%, DW-MRS25\%, and DW-MRS50\%) since the $\mathrm{pH}$ drop increased slightly in these cultures from 2.27 to 2.36 (Table 7, Figure 4). The absolute values of $b$ decreased slightly; meanwhile, the constant $c$ decreased from 0.103 to 0.022 because of the increase in the buffering capacity of media supplemented with increasing MRS nutrient concentrations from 0 to $50 \%$ [18]. This counteracted the reduction in $\mathrm{pH}$ values due to acid organic production by the nisin-producing strain.

However, the values of $a$ and $b$ had a positive value in the following cultures (fermentations DW-MR75\%, DW-MRS100\%, and DW-MRS125\%), and $c$ increased in DW-MRS100\% and DW-MRS125\% fermentations. The sign change observed for $a$ and $b$ from negative in the first three fermentations (DW-MR0\%, DW-MRS25\%, and DW-MRS50\%) to positive in the latter three cultures (DW-MR75\%, DW-MRS100\%, and DW-MRS125\%) could be related to the change in the trajectories described by the culture $\mathrm{pH}$. These $\mathrm{pH}$ trajectories evolved from convex curves in the first three cultures to inverted S-curves in the three latter cultures (Figure 4).

Thus, the values of $a, b$, and $c$ increased in the fermentation DW-MRS100\% compared to the fermentation DW-MRS75\% due to the increase in the growth of L. lactis. However, in the fermentation DW-MRS125\%, the increase in the buffering capacity of the supplemented media counteracted the effect of lactic acid production by the growing strain [18]. For this reason, the values of $a, b$, and $c$ decreased slightly (Table 7).

Regarding Equation (2), it can be noted that the values of $d$ and $e$ (with negative signs) increased and decreased, respectively, from the fermentation DW-MRS0\% to DW $-75 \%$ (Table 7). However, the sign of both constants becomes positive in the following fermentations due to the change in the curvature of the TN trajectories from convex curves (first four cultures) to inverted S-curves (fermentations DW-MRS100\% and DW-125\%), as observed before for the culture $\mathrm{pH}$ curves (Figure 4).

In fermentations DW-MRS0\% to DW-75\%, the values of $f$ and $h$ increased with nutrient supplementation since the addition of MRS nutrients led to an increase in the TN consumption, growth, and $\mathrm{pH}$ gradient. The latter probably affected the TN consumption rate since the consumption of this nutrient depends on the culture $\mathrm{pH}$, as explained above $[18,20]$. The constant $e$ varied as a function of the value of $d$ and the lowest TN concentration reached in the cultures, and $g$ was approximately constant $(-0.009 \pm 0.002)$ in the four fermentations (Table 7). In comparison with fermentation DW-MRS100\%, fermentation DW- $125 \%$ provided higher values of $d$ and $e$, in agreement with the increase in TN consumption in the latter culture. However, the value of $f$ decreased while those of $g$ and $h$ were constant in both cultures.

Equation (3) provided increasing values for $i$ due to the increase in the growth rates caused by the increase in MRS nutrient supplementation; meanwhile, the value of $j$ depended on the values of $i$ and the maximum biomass level reached in each culture. The values of $k(0.007 \pm 0.000)$ and $l(0.087 \pm 0.002)$ were almost constant, and $m$ showed an increasing trend.

In Equation (4), the values of $n$ increased with the increase in nutrient supplementation, indicating a stimulation in nisin production, and the values of the constant $o$ varied depending on the values of $n$ and the maximum nisin titers reached in the cultures. In addition, the values of $p$ and $r$ did not vary, but the constant $q$ increased (Table 7), probably because of the changes in the trajectories described by the culture $\mathrm{pH}$ that affected the evolution of nisin production in the cultures (Figure 4), as commented above [5,8,12].

In this series of cultures, the increase in the MRS nutrients added into the DW medium affected both the evolution of the culture variables and the final concentrations of biomass and nisin obtained (Figure 4), as well as the rates $r p H, r T N, r X$, and $r B T$ (Figure 7). The rates of culture $\mathrm{pH}$ decrease exhibited a transition from exponential decay-shaped curves (in the DW25, DW50, and DW75 media) to bell-shaped curves (in the DW100 and DW125 media); 
meanwhile, the $r T N, r X$, and $r B T$ profiles showed bell-shaped curves [25]. However, the $r p H, r T N, r X$, and $r B T$ profiles did not show an appreciable relationship (linear, quadratic, sigmoidal, etc.) with the initial MRS nutrient concentration ([Nut $\left.]_{0}\right)$ in the medium.
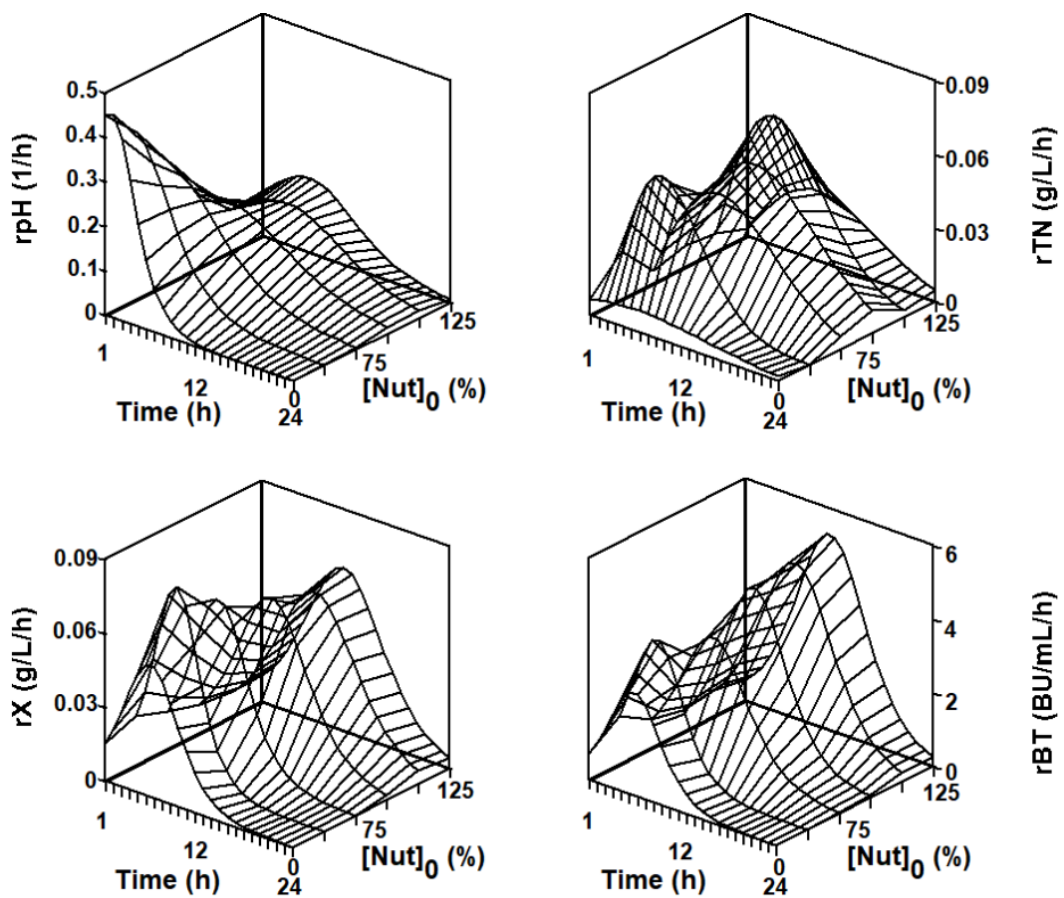

Figure 7. Response surfaces showing the time courses of the experimental rates of $\mathrm{pH}, \mathrm{TN}, \mathrm{X}$, and Nis as a function of the initial concentration of MRS both nutrients ([Nut $]_{0}=0,25,50,75,100$, and $125 \%$ ) in the DW medium. The different rates were obtained from the experimental data shown in Figure 4.

Therefore, in this case, it is also difficult to develop a general four-dimensional predator-prey system describing the evolution of $\mathrm{pH}, \mathrm{TN}, \mathrm{X}$, and $\mathrm{BT}$ as a function of the initial concentrations of MRS nutrients.

\subsection{Mathematical Analysis of the Four-Dimensional Lotka-Volterra Equation}

After demonstrating the feasibility of the designed four-dimensional Lotka-Volterra equation to describe the batch nisin production system in different batch cultures, the following step was focused on the mathematical study of the equation by determining its approximate solutions and analyzing its equilibrium points and trajectories around the stable equilibrium points.

\subsubsection{Generalized Four-Dimensional Lotka-Volterra Equation}

Given two column vectors of $\mathbb{R}^{n}, x$, and $y$, their component-by-component product can be defined by the following:

$$
x \cdot y=\left[\begin{array}{c}
x_{1} y_{1} \\
x_{2} y_{2} \\
\vdots \\
x_{n} y_{n}
\end{array}\right]
$$


Given $x \in \mathbb{R}^{\mathrm{n}}$ and $A \in \mathrm{M}_{\mathrm{n} \times \mathrm{n}}(\mathbb{R})$ we define the following:

$$
A \cdot x=\left[\begin{array}{c}
x_{1} A_{1} \\
x_{2} A_{2} \\
\vdots \\
x_{n} A_{n}
\end{array}\right]
$$

where $A_{i}$ is the i-th row of the matrix $A$.

The generalized Lotka-Volterra equations are given by the system of differential equations given by the following:

$$
x^{\prime}=x \cdot(b-A x)
$$

where $\mathrm{b}$ is a column vector and $A$ is a square matrix.

Lemma 1. Suppose $A$ is nonsingular. The Jacobian of $F(x)=x \cdot(b-A x)$ satisfies the following:

$$
\begin{aligned}
& J_{F}(\tilde{x})=-A \cdot \widetilde{x} \\
& \text { for } \tilde{x}=A^{-1} b .
\end{aligned}
$$

Proof. Note that

$$
F_{i}=\left(b_{i}-\sum_{j=1}^{n} a_{i j} x_{j}\right) x_{i}
$$

where it follows that

$$
\nabla F_{i}(x)=\left(-a_{i 1} x_{i},-a_{i 2} x_{i}, \ldots,-a_{i, i-1} x_{i},-a_{i i} x_{i}+b_{i}-\sum_{j=1}^{n} a_{i j} x_{j},-a_{i, i+1} x_{i}, \ldots,-a_{i n} x_{i}\right)
$$

Thus,

$$
\nabla F_{i}(\widetilde{x})=\left(-a_{i 1} \widetilde{x}_{i},-a_{i 2} \widetilde{x}_{i}, \ldots,-a_{i, i-1} \widetilde{x}_{i},-a_{i i} \widetilde{x}_{i},-a_{i, i+1} \widetilde{x}_{i}, \ldots,-a_{i, n} \widetilde{x}_{i}\right)=-\widetilde{x}_{i} A_{i}
$$

which proves the Lemma 1 .

As a consequence of the above lemma and the linearization theorem of Liapunov and Poincaré, the following theorem follows:

Theorem 1. If $A$ is nonsingular, the generalized Lotka-Volterra equations have a unique equilibrium point with all their entries different from zero, given by $\tilde{x}=A^{-1} b$. If, in addition, the matrix $A \cdot \tilde{x}$ has all its eigenvalues with a positive real part, then $\tilde{x}$ is asymptotically stable [26]. Note that, since $J_{F}(\tilde{x})=-A \cdot \tilde{x}$ that corresponds to the situation in which all the eigenvalues of the Jacobian have a negative real part.

\subsubsection{Numerical Analysis}

To perform the mathematical analysis of the four-dimensional LV-like equation designed in this work, we use the experimental data corresponding to the unsupplemented (first) culture of the DW-G series (Table 4). So that the analysis was carried out considering the following parameter values of: $a=-0.154, b=-0.037, c=0.039, d=-0.194, e=-0.909$, $f=-0.066, g=-0.002, h=0.034, i=0.843, j=0.787, k=0.008, l=0.066, m=-0.104$, $n=3.727, o=0.036, p=0.137, q=0.607$, and $r=-0.092$.

An interactive environment of MATLAB (app designer) from the function ode $45 . \mathrm{m}$ was developed to obtain approximate solutions to the four-dimensional LV-like equation for the desired initial conditions. In particular, for each equilibrium point $p\left(p_{1}, p_{2}, p_{3}, p_{4}\right)$ 
and $\varepsilon=\left(\varepsilon_{1}, \varepsilon_{2}, \varepsilon_{3}, \varepsilon_{4}\right)$, the approximate solutions $x_{\varepsilon}(t), y_{\varepsilon}(t), z_{\varepsilon}(t)$, and $w_{\varepsilon}(t)$, corresponding to the following initial conditions: $x_{0}=p_{1}+\varepsilon_{1}, y_{0}=p_{2}+\varepsilon_{2}, z_{0}=p_{3}+\varepsilon_{3}, w_{0}=p_{4}+\varepsilon_{4}$, can be calculated. Figure 8 shows the graphs corresponding to $x_{\varepsilon}(t), y_{\varepsilon}(t), \mathrm{z}_{\varepsilon}(t)$, and $w_{\varepsilon}(t)$ for 40 random values of $\varepsilon$ in the 4-dimensional sphere with the center at the origin and a radius of 0.01 .
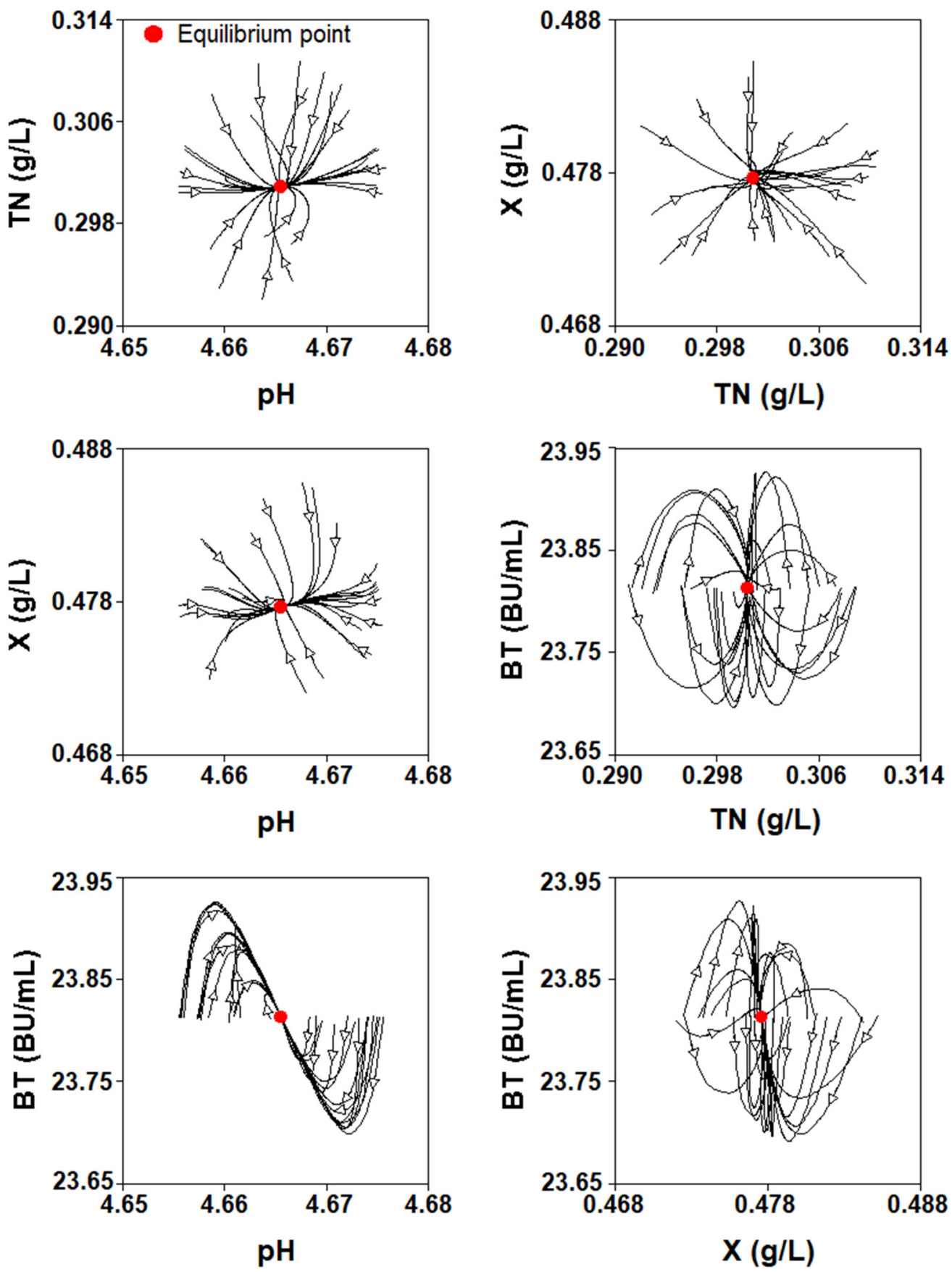

Figure 8. Family of trajectories for the four-dimensional Lotka-Volterra system around the equilibrium point $(\mathrm{pH}=4.665, \mathrm{TN}=0.301 \mathrm{~g} / \mathrm{L}, \mathrm{X}=0.477 \mathrm{~g} / \mathrm{L}, \mathrm{BT}=23.812 \mathrm{BU} / \mathrm{mL})$. 
The equilibrium points $(\mathrm{pH}(\mathrm{t}), \mathrm{TN}(\mathrm{t}), \mathrm{X}(\mathrm{t})$, and $\mathrm{BT}(\mathrm{t}))$ corresponding to the fourdimensional Lotka-Volterra equation were obtained by solving $\boldsymbol{x} \cdot(\boldsymbol{b}-\boldsymbol{A} \boldsymbol{x})=0$, where:

$$
\boldsymbol{x}=\left[\begin{array}{c}
p H \\
T N \\
X \\
B T
\end{array}\right], \boldsymbol{b}=\left[\begin{array}{c}
-a \\
-d \\
i \\
n
\end{array}\right], \boldsymbol{A}=\left[\begin{array}{cccc}
-b & 0 & -c & 0 \\
-h & -e & -f & -g \\
l & m & j & k \\
q & r & p & o
\end{array}\right]
$$

With this procedure, the following 16 equilibrium points were calculated: $\mathrm{P}_{1}(0.000,0.000,0.000,0.000), \quad \mathrm{P}_{2}(0.000,0.000,1.071,0.000), \quad \mathrm{P}_{3}(0.000,0.000,0.000,103.528)$, $\mathrm{P}_{4}(0.000,0.000,0.019,103.453), \mathrm{P}_{5}(0.000,0.213,0.000,0.000), \mathrm{P}_{6}(0.000,-0.014,0.000,103.491)$, $\mathrm{P}_{7}(0.000,0.134,1.089,0.000), \quad \mathrm{P}_{8}(0.000,-0.015,0.018,103.420), \quad \mathrm{P}_{9}(4.162,0.000,0.000,0.000)$, $\mathrm{P}_{10}(4.162,0.000,0.000,33.349), \quad \mathrm{P}_{11}(4.162,0.369,0.000,0.000), \quad \mathrm{P}_{12}(4.162,0.294,0.000,34.101)$, $\mathrm{P}_{13}(4.861,0.000,0.663,0.000), \mathrm{P}_{14}(4.627,0.000,0.441,23.837), \mathrm{P}_{15}(4.906,0.346,0.705,0.000)$, and $\mathrm{P}_{16}(4.665,0.301,0.477,23.812)$.

Of all, only the point $\mathrm{P}_{16}(4.665,0.301,0.477,23.812)$ has biological interest since the other equilibrium points contain at least one zero, and this implies that there are no viable cells $(X=0)$, nitrogen source $(\mathrm{TN}=0)$, or nisin $(\mathrm{BT}=0)$, or that the culture $\mathrm{pH}$ reached the value zero. However, in the fermentation analyzed, this was not possible because during the incubation, the culture variables were all greater than zero during the incubation period (Figure 1). At the beginning of fermentation, the values of the culture $\mathrm{pH},[\mathrm{TN}],[\mathrm{X}]$, and [BT] were $6.230,0.439 \mathrm{~g} / \mathrm{L}, 0.010 \mathrm{~g} / \mathrm{L}$, and $0.430 \mathrm{BU} / \mathrm{mL}$, respectively, and reached the final values of $4.730,0.319 \mathrm{~g} / \mathrm{L}, 0.480 \mathrm{~g} / \mathrm{L}, 22.897 \mathrm{BU} / \mathrm{mL}$, respectively.

So that, the unique equilibrium point $\left(\mathrm{P}_{16}\right)$ with all its components different from zero is as follows:

$$
\widetilde{x}=A^{-1} b=\left[\begin{array}{c}
4.665 \\
0.301 \\
0.477 \\
23.812
\end{array}\right]
$$

That satisfies:

$$
A \cdot \widetilde{x}=\left[\begin{array}{cccc}
0.1726 & 0 & -0.1819 & 0 \\
-0.0102 & 0.2735 & 0.0198 & 0.0006 \\
0.0315 & -0.0497 & 0.3759 & 0.0038 \\
14.4542 & -2.1907 & 3.2623 & 0.8572
\end{array}\right]
$$

The eigenvalues of this matrix are $0.4096,0.2875,0.8494$, and 0.1327 . By the previous Theorem, $\widetilde{x}$ is asymptotically stable.

Figure 9 shows how the calculated trajectories of the four culture variables evolve from different initial values to converge to their corresponding equilibrium point $(\mathrm{pH}=4.665, \mathrm{TN}=0.301 \mathrm{~g} / \mathrm{L}, \mathrm{X}=0.477 \mathrm{~g} / \mathrm{L}, \mathrm{BT}=23.812 \mathrm{BU} / \mathrm{mL})$.

As observed in Figure 9B, the four culture variables $(\mathrm{pH}, \mathrm{TN}, \mathrm{X}$, and $\mathrm{BT})$ gradually reach a plateau phase and stabilize at the above-mentioned stable equilibrium point. In fact, the coordinates of the latter point are in perfect agreement with the experimental values of the culture variables $(\mathrm{pH}=4.730, \mathrm{TN}=0.319 \mathrm{~g} / \mathrm{L}, \mathrm{X}=0.482 \mathrm{~g} / \mathrm{L}, \mathrm{BT}=22.905 \mathrm{BU} / \mathrm{mL})$ obtained after $17 \mathrm{~h}$ of incubation, from which the culture variables stabilized (Figure 1).

The phase graphs (Figure 10) show that there is an interaction between the four culture variables over time. Thus, the relationships between $\mathrm{TN}$ vs. $\mathrm{pH}$ and $\mathrm{BT}$ vs. $\mathrm{X}$ were directly proportional because $\mathrm{TN}$ concentration decreased with the decrease in $\mathrm{pH}$, and $\mathrm{BT}$ increased with the growth of L. lactis since this bacteriocin was produced in the logarithmic phase of growth as a primary metabolite (Figure 1). 


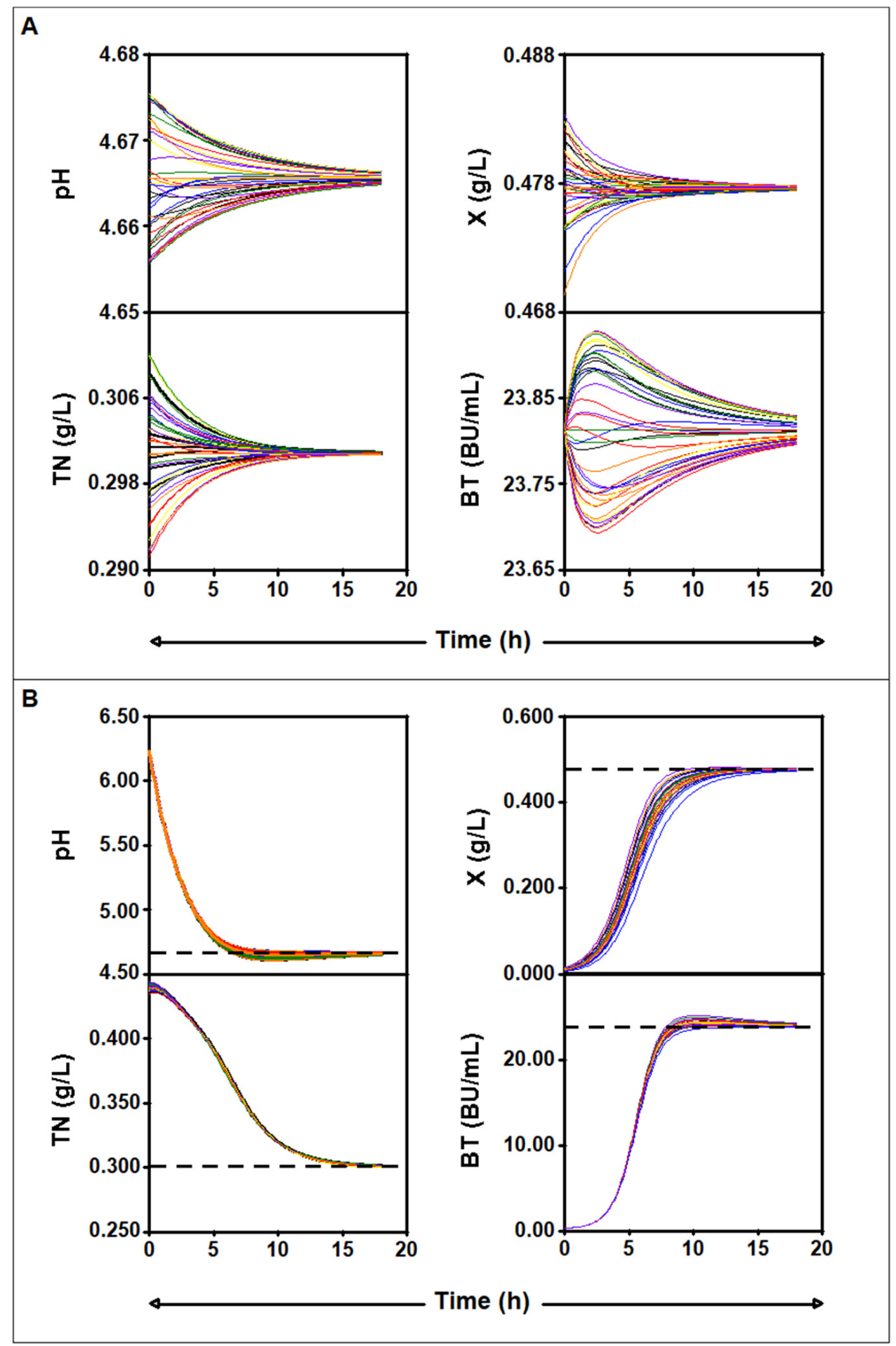

Figure 9. (A): Family of trajectories for the four-dimensional Lotka-Volterra system for $a=-0.154$, $b=-0.037, c=0.039, d=-0.194, e=-0.909, f=-0.066, g=-0.002, h=0.034, i=0.843, j=0.787$, $k=0.008, l=0.066, m=-0.104, n=3.727, o=0.036, p=0.137, q=0.607$, and $r=-0.092$. B: Family of trajectories obtained using the initial conditions $\left(\mathrm{pH}_{0}=6.230, \mathrm{TN}_{0}=0.439 \mathrm{~g} / \mathrm{L}, \mathrm{X}_{0}=0.010 \mathrm{~g} / \mathrm{L}\right.$, (B) $\mathrm{T}_{0}=0.430 \mathrm{BU} / \mathrm{mL}$ ) at the beginning of fermentation, which are in a neighborhood of the equilibrium point $\left(\mathrm{pH}=4.665, \mathrm{TN}_{0}=0.301 \mathrm{~g} / \mathrm{L}, \mathrm{X}=0.477 \mathrm{~g} / \mathrm{L}, \mathrm{BT}=23.812 \mathrm{BU} / \mathrm{mL}\right)$. 

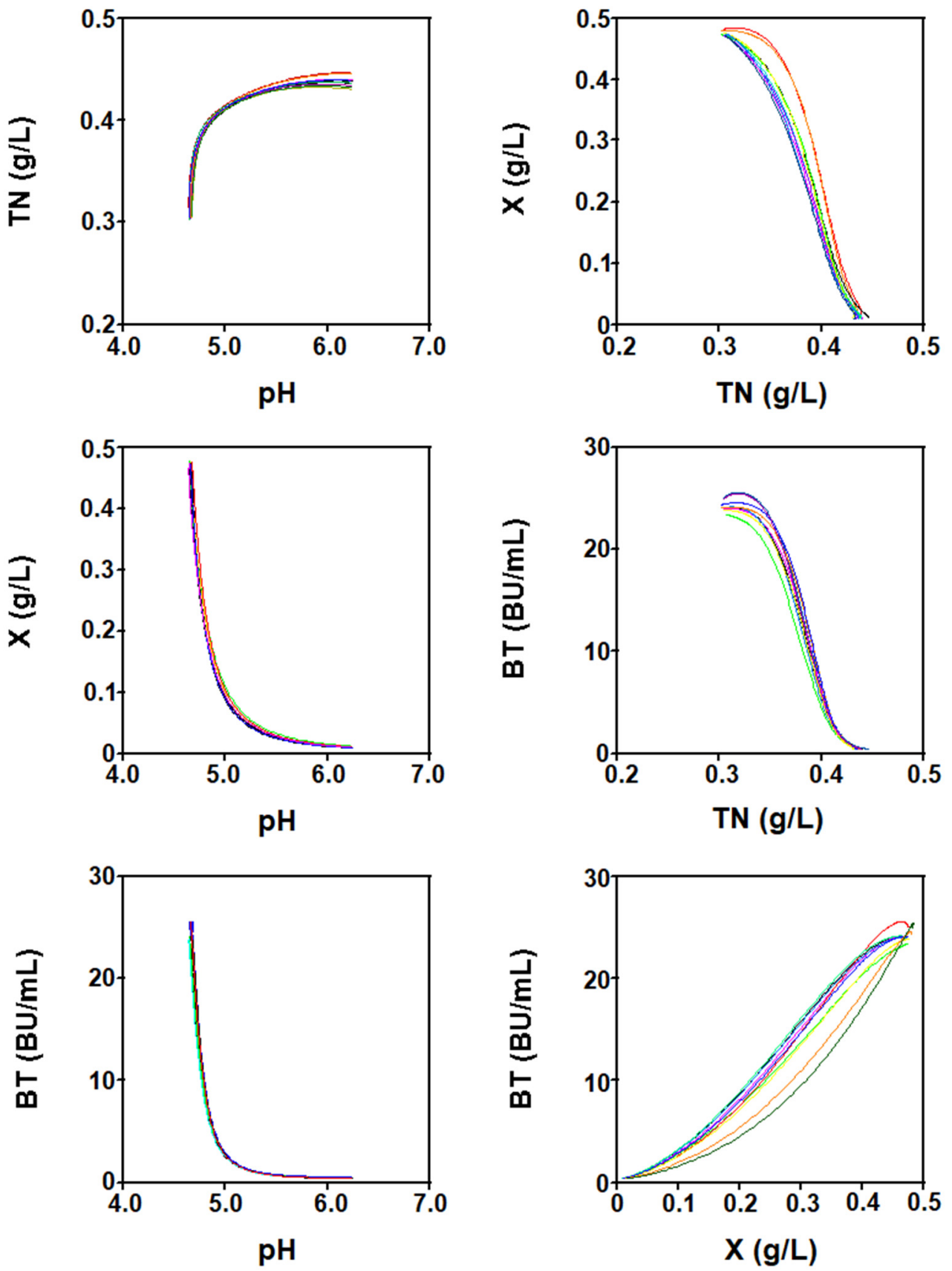

Figure 10. Phases plane diagram of the four-dimensional Lotka-Volterra-like equation.

In contrast, the relationships $X$ vs. $\mathrm{pH}, \mathrm{BT}$ vs. $\mathrm{pH}, \mathrm{X}$ vs. TN, and BT vs. TN were inversely proportional because the biomass and nisin synthesis increased with the decrease in $\mathrm{pH}$ and increase in TN consumption, which reduced the concentration of the nitrogen source (Figure 1).

On the other hand, closed elliptic orbits previously observed in classic predatorprey models were not observed when the four-dimensional LV-like equation was used to describe the batch nisin system, because these microbial relationships are not periodic, as those of the populations of predators and prey in biological systems [27].

2.4.3. Study of the Parameter Values for Which There Is an Asymptotically Stable Solution

In what follows, we will establish, by means of a Monte Carlo study [28,29], which conditions must be satisfied by the parameters defining the matrix $A$ and the vector $b$ so 
that the Lotka-Volterra equation has a single asymptotically stable equilibrium point with all its positive (and non-zero) coordinates.

If we denote by $\left\{p_{i}\right\}_{i=1}^{18}$ the generic parameters (i.e., $\left.a, b, c, d, e, f, g, h, i, j, k, l, m, n, o, p, q, r\right)$, and by $\left\{p_{i 0}\right\}_{i=1}^{18}$ the current parameters, the aim of our study is to look for positive values, $R_{1}$ and $R_{2}$, as large as possible, so that if

$p_{i} \in\left[p_{i 0}\left(1-R_{1}\right), p_{i 0}\left(1+R_{2}\right)\right]\left(\right.$ if $\left.p_{i} 0 \geq 0\right)$

$p_{i} \in\left[p_{i 0}\left(1+\mathrm{R}_{2}\right), p_{i 0}\left(1-R_{1}\right)\right]\left(\right.$ if $\left.p_{i} 0<0\right)$ being $i=1,2, \ldots, 18$

Then $\widetilde{x}=A^{-1} b$ satisfies that all its entries are positive and the matrix $A \cdot \widetilde{x}$ has all its eigenvalues with a positive real part.

For this purpose, we fixed $R_{1}$, and the step $\mathrm{h}=0.001$, and we determined the first value of a natural $k$ such that if $R_{2}=k \cdot h$, and 10.000 random values were taken for each one of the intervals $\left[p_{i 0}\left(1-R_{1}\right), p_{i 0}\left(1+R_{2}\right)\right]$ (if $\left.p_{i} 0 \geq 0\right)$ and $\left[p_{i 0}\left(1+R_{2}\right), p_{i 0}\left(1-R_{1}\right)\right]$ (if $p_{i} 0<0$ ), then $\widetilde{x}=A^{-1} \boldsymbol{b}$ has any of its entries nonpositive or the matrix $\boldsymbol{A} \cdot \widetilde{x}$ has some eigenvalue with a nonpositive real part.

We observed that if $R_{1}>0.12$, there are no asymptotically stable equilibrium points with all their non-zero coordinates. The left and right parts of Figure 11 show the curve $R_{1} \rightarrow R_{2}$ and the curves $R_{1} \rightarrow 1-R_{1}$ and $R_{1} \rightarrow 1+R_{2}$, respectively. As can be observed in these figures, the range of the parameters' validity is approximately equal to $0.12\left|p_{i 0}\right|$, $i=1,2, \ldots, 18$.
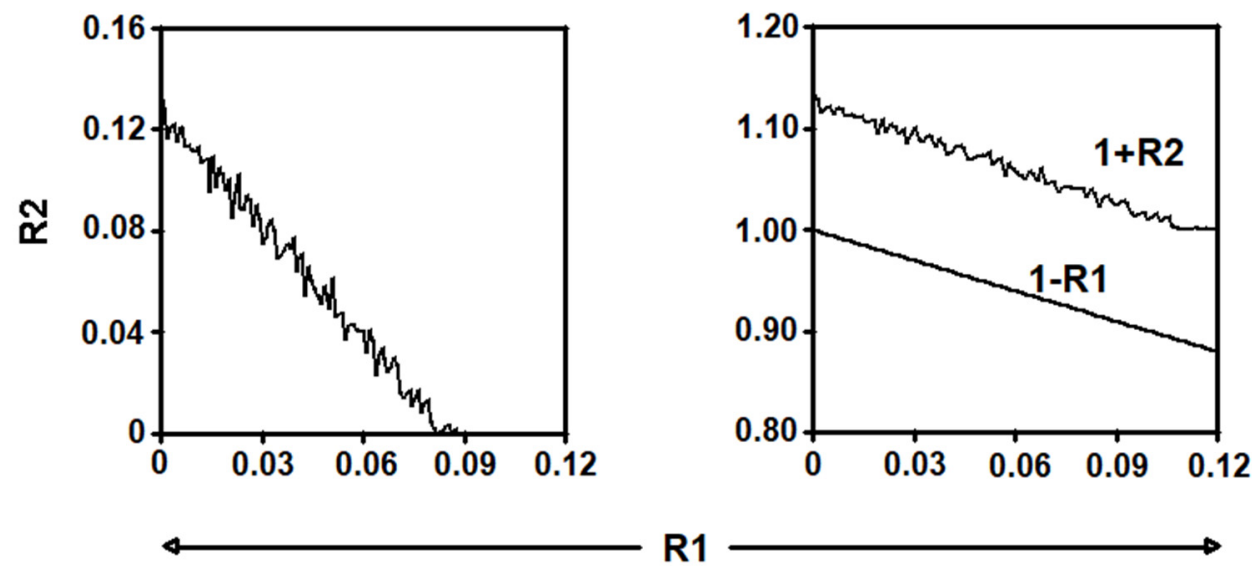

Figure 11. Plots of the curves $R_{1} \rightarrow R_{2}$ (left part), and $R_{1} \rightarrow 1-R_{1}$ and $R_{1} \rightarrow 1+R_{2}$ (right part).

\section{Materials and Methods}

\subsection{Microorganisms, Culture Media, and Inoculum Preparation}

In this work, Lactococcus lactis CECT 539 and Carnobacterium piscicola CECT 4020 were used as the nisin-producing strain and target bacterium (in the nisin activity bioassay), respectively. Both strains were obtained from the Spanish Type Culture Collection (CECT) and cultured at $30^{\circ} \mathrm{C}$ in MRS (de Man, Rogosa and Sharpe) agar slants or broth.

Diluted whey (DW) and concentrated mussel-processing waste (CMPW) were used to prepare the different culture media (Table 1). Sterilization $\left(121^{\circ} \mathrm{C} / 15 \mathrm{~min}\right)$ of these substrates led to the precipitation of a protein fraction that interfered with biomass measurements. For this reason, the precipitated material was removed by acidification of the DW and CMPW substrates to $\mathrm{pH} 4.5$ with $5 \mathrm{~N} \mathrm{HCl}$, heating $\left(121^{\circ} \mathrm{C} / 15 \mathrm{~min}\right)$ and centrifugation $(12,000 \times g$ for $15 \mathrm{~min})$ [16-18].

Given that the nisin-producing strain is not an amylolytic bacterium, the glycogen contained in the CMPW was enzymatically hydrolyzed to produce a glucose-containing substrate as described in Costas et al. [17].

To prepare the different fermentation substrates, DW medium was supplemented with the following nutrients: (i) different amounts of glucose to obtain 5, 10, 15, 20, and 25 g glucose/L of medium (series of fermentation DW-G) [16], (ii) different volumes of CMPW medium (101.33 g glucose/L) and amounts of $\mathrm{KH}_{2} \mathrm{PO}_{4}$ to obtain initial total sugars 
and phosphorous concentrations between 22.61 and $51.35 \mathrm{~g} / \mathrm{L}$, and 0.24 and $0.63 \mathrm{~g} / \mathrm{L}$, respectively (series of fermentation DW-TS-TP) [17], and (iii) MRS broth nutrients (except glucose and Tween 80$)$ at 25, 50, 75, 100, and 125\% (w/v) of their standard concentrations in the complex substrate to produce the DW25, DW50, DW75, DW100, and DW125 media (series of fermentation DW-MRS) [18]. In these three series of fermentation, control cultures in unsupplemented DW medium were performed to obtain data for the comparisons [16-18].

Tables 1 and 2 show the mean compositions of the resulting culture media used in this work.

To prepare the preculture, cells of L. lactis CECT 539 from MRS agar slants were used to inoculate sterile MRS broth $(10 \mathrm{~mL})$ and incubated at $30^{\circ} \mathrm{C}$ for $12 \mathrm{~h}$ with shaking at $200 \mathrm{rpm}$. After that, $50 \mathrm{~mL}$ of inoculum medium (which was, in each case, similar to the corresponding fermentation substrate) were inoculated with $1 \mathrm{~mL}$ of the preculture and subsequently incubated for $12 \mathrm{~h}$ at $30^{\circ} \mathrm{C}$ with shaking at $200 \mathrm{rpm}$. An appropriate volume of the latter culture was used to inoculate the corresponding fermentation medium used in the different batch cultures to give an initial viable cell count of $1.5 \times 10^{9}$ colony-forming units/mL [16-18].

\subsection{Batch Cultures}

The different experimental data used in this research were collected from previous batch cultures of L. lactis CECT 539 [16-18]. The fermentations were conducted in duplicate in $250 \mathrm{~mL}$ Erlenmeyer flasks that contained $50 \mathrm{~mL}$ of the corresponding DW-based medium. After inoculation, the flasks were incubated at $30^{\circ} \mathrm{C}$ with shaking at $200 \mathrm{rpm}$ for $18 \mathrm{~h} \mathrm{[16],}$ $21 \mathrm{~h} \mathrm{[17],} \mathrm{and} 24 \mathrm{~h}$ [18].

\subsection{Analytical Methods}

The corresponding analytical methods used to measure culture $\mathrm{pH}$ and concentrations of total nitrogen, biomass, and nisin were previously described in Costas et al. [16].

\subsection{Statistical Significance of the Parameters and Equation}

Before being used to fit the four-dimensional predator-prey system, the experimental data of the culture $\mathrm{pH}$ and remaining concentrations of total nitrogen, biomass, and nisin [16-18] were smoothed using the following logistic equations (5-7):

For the culture $\mathrm{pH}(Q(t)=p H(t))$ and total nitrogen $(Q(t)=T N(t))$ decrease, we modified the logistic decline equation presented by Goudar et al. [28] as follows:

$$
Q(t)=\frac{A}{B-e^{\left(C_{0}+C_{1} \cdot t+C_{2} \cdot t^{2}\right)}}
$$

Being $A=\frac{p H_{0} \cdot p H_{f}}{p H_{0}-p H_{f}}$ for culture $\mathrm{pH}$ or $A=\frac{T N_{0} \cdot T N_{f}}{T N_{0}-T N_{f}}$ for TN.

and $B=\frac{p H_{0}}{p H_{0}-p H_{f}}$ for culture $\mathrm{pH}$ or $B=\frac{T N_{0}}{T N_{0}-T N_{f}}$ for TN.

For biomass $(X(t))$ production, the logistic equation presented by Goudar et al. [30] was used by considering that the death cell rate was zero, as follows:

$$
X(t)=\frac{D}{1+E \cdot e^{-F \cdot t}}
$$

Being $D=X_{\max }$ and $E=\frac{X_{\max }-X_{o}}{X_{o}}$.

For nisin $(B T(t))$ synthesis, we modified the logistic decline equation [30] as follows:

$$
B T(t)=\frac{G}{1+H \cdot e^{(-I \cdot t)}}-\frac{G}{1+H}
$$

Being $G=B T_{\max }$. 
In this work, the values of the different constants were first obtained by numerical integration of the four differential equations $(d p H(t) / d t, d T N(t) / d t, d X(t) / d t$, and $d B T(t) / d t)$ of the competitive predator-prey system (1)-(4), minimizing the sum of quadratic differences between equation-predicted and experimental values, with the non-linear least squares (quasi-Newton) method included in the Solver tool of Microsoft Excel 2016 spreadsheet. Then, the values and statistical significance $(p<0.05)$ of both the constants and the four-dimensional Lotka-Volterra-like equation were corroborated with an accurate statistical analysis using the statistics software SigmaPlot for Windows version 12.0 (Systat Software, Inc., San Jose, CA, USA, 2012) and the Regression (non-lineal) module of the software package IBM SPSS Statistics 20.0 for Windows (Release 20.0.1; SPSS Inc., Chicago, IL, USA, 2021). The significance of the different constants in each differential equation was evaluated by using Student's $t$-test and considering the corresponding $p$ values [31] for each constant. Thus, the values of the constants with a high $t$-value and a $p$ value lower than 0.05 were considered statistically significant. The significance of the different constants in each differential equation was evaluated by using Student's $t$-test and considering the corresponding $p$ values for each constant. The convergence of the parameters was checked by using the Levenberg-Marquardt method [32,33] of the Regression (non-lineal) module of the software package IBM SPSS Statistics 20.0 for Windows (Release 20.0.1; SPSS Inc., Chicago, IL, USA, 2021).

The global consistency of the four differential equations was verified by using the overall Fisher's F-test $(\alpha=0.05)$ and considering the corresponding $p$ values for each equation. Thus, a high $F$-value and a $p$ value lower than 0.05 means that the differential equation was statistically significant.

The goodness-of-fit of the four differential equations was also checked using the mean relative percentage deviation modulus (RPDM) values [5] and the bias $\left(B_{f}\right)$ and accuracy $\left(A_{f}\right)$ factors [34]:

$$
\begin{gathered}
\text { RPDM }=\frac{100}{n} \sum\left|\frac{\text { exp }_{i}-Y_{\text {pred }_{i}}}{\exp _{i}}\right| \\
B_{f}=10^{\frac{\sum \log \left(\frac{\text { Yred }_{i}}{\text { Yexp }_{i}}\right)}{s}} \\
A_{f}=10^{\frac{\sum \log \left(\frac{Y_{\text {pred }}}{\text { Yexp }_{i}}\right) \mid}{s}}
\end{gathered}
$$

where $s$ is the number of experimental data, $Y \exp _{i}$ is the experimental value and Ypred ${ }_{i}$ is the value predicted by the equation. Values of $R^{2} \geq 0.95, R P D M<10 \%$ [5], and $B_{f}$ and $A_{f}$ close to 1 [34] indicate that the corresponding equation was accurately fitted to the experimental data.

\subsection{Mathematical Analysis}

The mathematical analysis of the four-dimensional Equation (Equations (1)-(4)) was performed with the MATLAB Runtime R2021a (MathWorks Inc., Natick, MA, USA) using the values of the constants corresponding to the unsupplemented culture of the DW-G series.

\section{Conclusions}

The main contribution of this paper is the development and mathematical analysis, for the first time, of a four-dimensional predator-prey system for an accurate description of the batch nisin production system by L. lactis CECT 539 in different series of fermentation in DW media supplemented with different concentrations of glucose (DW-G cultures), total sugars and phosphorous (DW-TS-TP cultures), or MRS broth nutrients (DW-MRS cultures).

The results obtained in this paper demonstrated that the microbiological bacteriocin production system could be explained by considering the biological approach used to describe the relationships between species that compete for the same nutrient sources. Thus, further knowledge is provided about the relationship between the main culture variables 
(culture $\mathrm{pH}$, total nitrogen consumption, and the synthesis of biomass and bacteriocin) involved in nisin production, which is usually difficult to explain.

The mathematical novelty of this paper relies on the determination, for the first time, of the equilibrium points and trajectories around the stable equilibrium point obtained from the mathematical analysis of the four-dimensional model designed in this paper. Thus, the existence of an asymptotically stable equilibrium point with biological sense $(\mathrm{pH}=4.665, \mathrm{TN}=0.301 \mathrm{~g} / \mathrm{L}, \mathrm{X}=0.477 \mathrm{~g} / \mathrm{L}, \mathrm{BT}=23.812 \mathrm{BU} / \mathrm{mL})$, to which the culture evolved to reach the stationary state, was proved. The existence of this equilibrium point is in perfect agreement with the experimental point $(\mathrm{pH}=4.730, \mathrm{TN}=0.319 \mathrm{~g} / \mathrm{L}$, $\mathrm{X}=0.482 \mathrm{~g} / \mathrm{L}, \mathrm{BT}=22.905 \mathrm{BU} / \mathrm{mL}$ at $17 \mathrm{~h}$ of fermentation), from which the four culture variables stabilized.

Author Contributions: Conceptualization, J.C.M., R.J.B.-J. and N.P.-G.; Methodology, F.G.-P., P.F.d.C. and N.P.-G.; Software, F.G.-P., P.F.d.C. and N.P.-G.; Validation, F.G.-P., P.F.d.C. and N.P.-G.; Formal Analysis, F.G.-P., P.F.d.C. and N.P.-G.; Investigation, R.J.B.-J. and N.P.-G.; Resources, N.P.-G. and R.J.B.-J.; Data Curation, F.G.-P., P.F.d.C. and N.P.-G.; Writing—Original Draft Preparation, F.G.-P., P.F.d.C. and N.P.-G.; Writing-Review \& Editing, J.C.M. and N.P.-G.; Visualization, N.P.-G. and J.C.M.; Supervision, N.P.-G. and R.J.B.-J.; Project Administration, N.P.-G. and J.C.M. All authors have read and agreed to the published version of the manuscript.

Funding: Financial support from Xunta de Galicia (ED431C2018/42-GRC) and the European Regional Development Fund (ERDF) is gratefully acknowledged.

Institutional Review Board Statement: Not applicable.

Informed Consent Statement: Not applicable.

Data Availability Statement: Data are available in the manuscript.

Conflicts of Interest: The authors declare no conflict of interest.

\section{Nomenclature}

$p H(t)$

$p \mathrm{H}_{0}$

$p H_{f}$

$a$

$b$

C

$T N(t)$

$T N_{0}$

$T N_{f}$

$d$

$e$

f

$g$

h

$X(t)$

$X_{0}$

$X_{\max }$

$i$

j
Time (h)

Culture $\mathrm{pH}$ value over the time

Initial culture $\mathrm{pH}$ value

Final culture $\mathrm{pH}$

Intrinsic $\mathrm{pH}$ drop rate $\left(\mathrm{h}^{-1}\right)$

Quotient between the intrinsic $\mathrm{pH}$ drop rate and the theoretical minimum $\mathrm{pH}$ value for growth $\left(\mathrm{h}^{-1}\right)$

Constant that represents the effect of biomass production on $\mathrm{pH}$ time course $(\mathrm{L} / \mathrm{g} / \mathrm{h})$

Total nitrogen concentration $(\mathrm{g} / \mathrm{L})$ over the time

Initial total nitrogen concentration $(\mathrm{g} / \mathrm{L})$

Final total nitrogen concentration $(\mathrm{g} / \mathrm{L})$

Intrinsic TN consumption rate $\left(\mathrm{h}^{-1}\right)$

Quotient between the intrinsic TN consumption rate and the theoretical maximum TN concentration that biomass can consume $(\mathrm{L} / \mathrm{g} / \mathrm{h})$

Intrinsic $\mathrm{TN}$ consumption rate $(\mathrm{L} / \mathrm{g} / \mathrm{h})$ for biomass production

Intrinsic $\mathrm{TN}$ consumption rate $(\mathrm{mL} / \mathrm{BU} / \mathrm{h})$ for nisin production

Constant that represents the effect of $\mathrm{pH}$ time course on TN consumption $\left(\mathrm{h}^{-1}\right)$

Biomass concentration $(\mathrm{g} / \mathrm{L})$ over the time

Initial biomass concentration $(\mathrm{g} / \mathrm{L})$

Maximum biomass concentration $(\mathrm{g} / \mathrm{L})$

Intrinsic growth rate $\left(\mathrm{h}^{-1}\right)$

Quotient between the intrinsic growth rate and the theoretical maximum biomass concentration that system can support $(\mathrm{L} / \mathrm{g} / \mathrm{h})$ 
k

$l$

$m$

$B T(t)$

$B T_{\text {max }}$

n

$p$

$q$

A, B, C $, C_{1}, C_{2}$
$D, E, F$
$G, H, I$
$[G]_{0}$
$[N u t]_{0}$
RPDM
$B_{f}$
$A_{f}$
s
Yexp

Ypred $_{i}$
R $^{2}$

Efficiency of TN utilization (mL/BU/h) to be channeled into cells of $L$. lactis rather than nisin (competition coefficient)

Constant that represents the effect of $\mathrm{pH}$ time course on the growth $\left(\mathrm{h}^{-1}\right)$ Constant that represents the effect of TN time course on the growth $(\mathrm{L} / \mathrm{g} / \mathrm{h})$

Nisin concentration $(\mathrm{BU} / \mathrm{mL})$ over the time

Maximum nisin concentration $(\mathrm{BU} / \mathrm{mL})$

Intrinsic nisin production rate $\left(\mathrm{h}^{-1}\right)$

Quotient between the intrinsic nisin production rate and the theoretical maximum nisin concentration that biomass can produce $\left(\mathrm{h}^{-1}\right)$

Efficiency of TN utilization ( $\mathrm{mL} / \mathrm{BU} / \mathrm{h}$ ) to be channeled into nisin rather than cells of L. lactis (competition coefficient)

Constant that represents the effect of $\mathrm{pH}$ time course on nisin synthesis $\left(\mathrm{h}^{-1}\right)$

Constant that represents the effect of TN time course on nisin synthesis $(\mathrm{L} / \mathrm{g} / \mathrm{h})$

Constants in Equation (5)

Constants in Equation (6)

Constants in Equation (7)

Initial glucose concentration $(\mathrm{g} / \mathrm{L})$

Initial concentration of MRS broth nutrients $(\mathrm{g} / \mathrm{L})$

Mean relative percentage deviation modulus

Bias factor

Accuracy factor

Number of experimental data

Experimental values of culture $\mathrm{pH}$ and concentration of total nitrogen, biomass, and nisin

Predicted values by the corresponding equation for culture $\mathrm{pH}$ and concentration of total nitrogen, biomass, and nisin.

Correlation coefficient

\section{References}

1. Delves-Broughton, J. Nisin. In Encyclopedia of Food Microbiology, 2nd ed.; Robinson, R., Batt, C.A., Tortorello, M.L., Eds.; Academic Press: London, UK, 2014; pp. 187-193.

2. Leroy, F.; De Vuyst, L. Growth of the bacteriocin-producing Lactobacillus sakei strain CTC 494 in MRS broth is strongly reduced due to nutrient exhaustion: A nutrient depletion model for the growth of lactic acid bacteria. Appl. Environ. Microbiol. 2001, 67, 4407-4413. [CrossRef] [PubMed]

3. van Impe, J.F.; Poschet, F.; Geeraerd, A.H.; Vereecken, K.M. Towards a novel class of predictive microbial growth models. Int. J. Food Microbiol. 2005, 100, 97-105. [CrossRef] [PubMed]

4. Wachenheim, D.E.; Patterson, J.A.; Ladisch, M.R. Analysis of the logistic function model: Derivation and applications specific to batch cultured microorganisms. Bioresour. Technol. 2003, 86, 157-164. [CrossRef]

5. Guerra, N.P.; Torrado, A.; López, C.; Fajardo, P.; Pastrana, L. Dynamic mathematical models to describe the growth and nisin production by Lactococcus lactis subsp. lactis CECT 539 in both batch and re-alkalized fed-batch cultures. J. Food Eng. 2007, 82, 103-113.

6. Vázquez, J.A.; Murado, M.A. Unstructured mathematical model for biomass, lactic acid and bacteriocin production by lactic acid bacteria in batch fermentation. J. Chem. Technol. Biotechnol. 2008, 83, 91-96. [CrossRef]

7. Shirsat, N.; Mohd, A.; Whelan, J.; English, N.J.; Glennon, B.; Al-Rubeai, M. Revisiting Verhulst and Monod models: Analysis of batch and fed-batch cultures. Cytotechnology 2015, 67, 515-530. [CrossRef]

8. Guerra, N.P. Modeling the batch bacteriocin production system by lactic acid bacteria by using modified three-dimensional Lotka-Volterra equations. Biochem. Eng. J. 2014, 88, 115-130. [CrossRef]

9. Callewaert, R.; De Vuyst, L. Bacteriocin production with Lactobacillus amylovorus DCE 471 is improved and stabilized by fed-batch fermentation. Appl. Environ. Microbiol. 2000, 66, 606-613. [CrossRef]

10. Wick, L.M.; Weilenmann, H.; Egli, T. The apparent clock-like evolution of Escherichia coli in glucose-limited chemostats is reproducible at large but not at small population sizes and can be explained with Monod kinetics. Microbiology 2002, 148, 2889-2902. [CrossRef]

11. Luedeking, R.; Piret, E.L. A kinetic study of the lactic acid fermentation. Batch process at controlled pH. J. Biochem. Microbiol. Technol. Eng. 1959, 1, 393-412. [CrossRef] 
12. Cabo, M.L.; Murado, M.A.; González, M.P.; Pastoriza, L. Effects of aeration and pH gradient on nisin production: A mathematical model. Enzym. Microb. Technol. 2001, 29, 264-273. [CrossRef]

13. Constandinides, K.; Damianou, P.A. Lotka-Volterra equations in three dimensions satisfying the Kowalevski-Painlevé property Regul. Chaotic Dyn. 2011, 16, 311-328. [CrossRef]

14. Yang, R.; Ray, B. Factors influencing production of bacteriocins by lactic acid bacteria. Food Microbiol. 1994, 11, 281-291. [CrossRef]

15. Wang, R.; Xiao, D. Bifurcations and chaotic dynamics in a 4-dimensional competitive Lotka-Volterra system. Nonlinear Dyn. 2010, 59, 411-422. [CrossRef]

16. Costas, M.; Alonso, E.; Guerra, N.P. Nisin production in realkalized fed-batch cultures in whey with feeding with lactose- or glucose-containing substrates. Appl. Microbiol. Biotechnol. 2016, 100, 7899-7908. [CrossRef]

17. Costas, M.; Alonso, E.; Outeiriño, D.; Guerra, N.P. Production of a highly concentrated probiotic culture of Lactococcus lactis CECT 539 containing high amounts of nisin. 3-Biotech 2018, 8, 292.

18. Costas, M.; Alonso, E.; Bazán, D.L.; Bendaña, R.J.; Guerra, N.P. Batch and fed-batch production of probiotic biomass and nisin in nutrient-supplemented whey media. Braz. J. Microbiol. 2019, 50, 915-925.

19. Urbansky, E.T.; Schock, M.R. Understanding, deriving, and computing buffer capacity. J. Chem. Educ. 2000, 77, 1640-1644. [CrossRef]

20. Poolman, B.; Konings, W.N. Relation of growth of Streptococcus lactis and Streptococcus cremoris to amino acid transport. J. Bacteriol. 1988, 170, 700-707. [CrossRef]

21. Abbasiliasi, S.; Tan, J.S.; Ibrahim, T.A.T.; Bashokouh, F.; Ramakrishnan, N.R.; Mustafa, S.; Arif, A.B. Fermentation factors influencing the production of bacteriocins by lactic acid bacteria: A review. RSC Adv. 2017, 7, 29395-29420. [CrossRef]

22. Salaün, F.; Mietton, B.; Gaucheron, F. Buffering capacity of dairy products. Int. Dairy J. 2005, 15, 95-109. [CrossRef]

23. Parente, E.; Ricciardi, A.; Addario, G. Influence of $\mathrm{pH}$ on growth and bacteriocin production by Lactococcus lactis subsp. lactis 14ONWC during batch fermentation. Appl. Microbiol. Biotechnol. 1994, 41, 388-394. [CrossRef]

24. van Niel, E.W.J.; Hahn-Hägerdal, B. Nutrient requirements of lactococci in defined growth media. Appl. Microbiol. Biotechnol. 1999, 52, 617-627. [CrossRef]

25. Moret-Tatay, C.; Gamermann, D.; Navarro-Pardo, E.; Fernández de Córdoba, P. ExGUtils: A python package for statistical analysis with the ex-gaussian probability density. Front. Psychol. 2018, 9, 612. [CrossRef]

26. Hsu, S.-B.; Ruan, S.; Yang, T.-H. Analysis of three species Lotka-Volterra food web models with omnivory. J. Math. Anal. Appl. 2015, 426, 659-687. [CrossRef]

27. Adamu, H.A. Mathematical analysis of predator-prey model with two preys and one predator. Int. J. Eng. Appl. Sci. 2018, 5, 17-23.

28. Castro-Palacio, J.C.; Isidro, J.M.; Navarro-Pardo, E.; Velázquez-Abad, L.; Fernández-de-Córdoba, P. Monte Carlo Simulation of a modified Chi distribution with unequal variances in the generating gaussians. A Discrete Methodology to Study Collective Response Times. Mathematics 2021, 9, 77. [CrossRef]

29. Ortigosa, N.; Orellana-Panchame, M.; Castro-Palacio, J.C.; Fernández de Córdoba, P.; Isidro, J.M. Monte Carlo simulation of a modified Chi distribution considering asymmetry in the generating functions: Application to the Study of Health-Related Variables. Symmetry 2021, 13, 924. [CrossRef]

30. Goudar, C.T.; Joeris, K.; Konstantinov, K.B.; Piret, J.M. Logistic equations effectively model mammalian cell batch and fed-batch kinetics by logically constraining the fit. Biotechnol. Prog. 2005, 21, 1109-1118. [CrossRef] [PubMed]

31. Tomás Miguel, J.M.; Meléndez Moral, J.C.; Navarro Pardo, E. Factorial confirmatory models of Ryff's scales in a sample of elderly people. Psicothema 2008, 20, 304-310. [PubMed]

32. Kanzow, C.; Yamashita, N.; Fukushima, M. Levenberg-Marquardt methods with strong local convergence properties for solving nonlinear equations with convex constraints. J. Comput. Appl. Math. 2004, 172, 375-397. [CrossRef]

33. Behling, R.; Gonçalves, D.S.; Santos, S.A. Local convergence analysis of the Levenberg-Marquardt framework for nonzero-residue nonlinear least-squares problems under an error bound condition. J. Optim. Theory Appl. 2019, 183, 1099-1122. [CrossRef]

34. Vazquez, J.A.; Lorenzo, J.M.; Fuciños, P.; Franco, D. Evaluation of non-linear equations to model different animal growths with mono and bisigmoid profiles. J. Theor. Biol. 2012, 314, 95-105. [CrossRef] [PubMed] 